\section{LA RECOGIDA DE BASURA EN MEGA-CIUDADES: En el marco de la sostenibilidad'}

Fabian Tron ${ }^{2}$

\section{Resumen}

La comprensión de las sociedades urbanas complejas sólo es posible cuando se estudia tanto el sector formal como el informal que las conforma. Para explicar ambos modelos, el rubro de los Residuos surge como una de las herramientas más competentes, capaz de distinguir entre ellos, incluso cuando la demanda de la sociedad supera su marco legislativo. Un cambio de enfoque en el que se define a los residuos sólidos en función a su potencial como recurso, contextualiza realidades muy divergentes. Con esta acepción, la gestión de residuos dentro de las ciudades de Tokio, México, Madrid y Paris puede ser estudiada a profundidad, denotando sus principales diferencias operativas y principales vulnerabilidades.

\section{WASTE COLLECTION IN MEGA-CITIES. Within the framework of sustainability ${ }^{1}$}

Fabian Tron ${ }^{2}$

\section{Abstract}

Understanding complex urban societies is only possible when their formal and informal aspects are studied. One of the strongest tools for this task is the study of waste, as it enables a distinction between these two aspects, even when the demands of society exceed the legislative framework. By defining waste as a resource, it normalizes vastly dissimilar realities. Then, waste management in cities such as Tokyo, Mexico City, Madrid and Paris can be thoroughly studied, coming into light their operational differences as well as their vulnerabilities. 
En este artículo se demuestra cómo, una vez evidenciadas las particularidades, es posible relacionar la interacción de las ciudades frente a los vacíos del marco normativo. Una comparación que destaca la capacidad innata de las sociedades a adaptarse a dichas imperfecciones, llegando a una mejor comprensión de los alcances del sector informal que, particularmente dentro de los países en desarrollo, contribuye a la eficiencia del sistema urbano.

\section{PALABRAS CLAVES: RESIDUOS SÓLIDOS, MEGA- CIUDADES, SECTOR INFORMAL, RECURSOS, VERTEDEROS.}

Fecha de recepción: 01.03.10

Fecha de aceptación: 03.10.10

1 El trabajo empieza como una interrogante a los sistemas de gestión de residuos dentro del marco de la sostenibilidad ambiental.

Desarrollado a lo largo de un año, dentro del programa de Doctorado de Periferias, Sostenibilidad y Vitalidad Urbana, bajo la tutela del Dr. Agustín Hernández-Aja y asesorado por Alfonso del Val (Becado por el CONACYT).

2 México. Arquitecto- Urbanista. Doctorando del Departamento de Urbanismo y Ordenación del Territorio de la Escuela Técnica Superior de Arquitectura de Madrid (ETSAM). Tron Arquitectos S.C. México D.F.

Correo electrónico: metaarquitectura@gmail.com
This article shows the relation between the interaction of cities and normative gaps. Through this comparison, the innate capacity of societies to adapt to these imperfections is highlighted, being useful to understand the informal sector and its contribution to the efficiency of the urban system, especially in developing countries.

\section{KEYWORDS: SOLID WASTE, MEGA-CITIES, INFORMAL SECTOR, RESOURCES, DUMPING SITES.}

Received: 01.03.10

Accepted: 03.10.10

1 Developed for a year, as part of the Doctorate Program on Periphery, Sustainability and Urban Vitality, guided by Agustín Hernandez-Aja, Ph.D., and supervised by Alfonso del Val, this article (funded by CONACYT) questions waste management systems within the framework of environmental sustainability

2 Mexican, Architect-Town Planner. Ph.D., Department of Town Planning, Higher Technical School of Arquitecture of Madrid. Tron Arquitectos S.C. Mexico D.F. Email: metaarquitectura@gmail.com. 


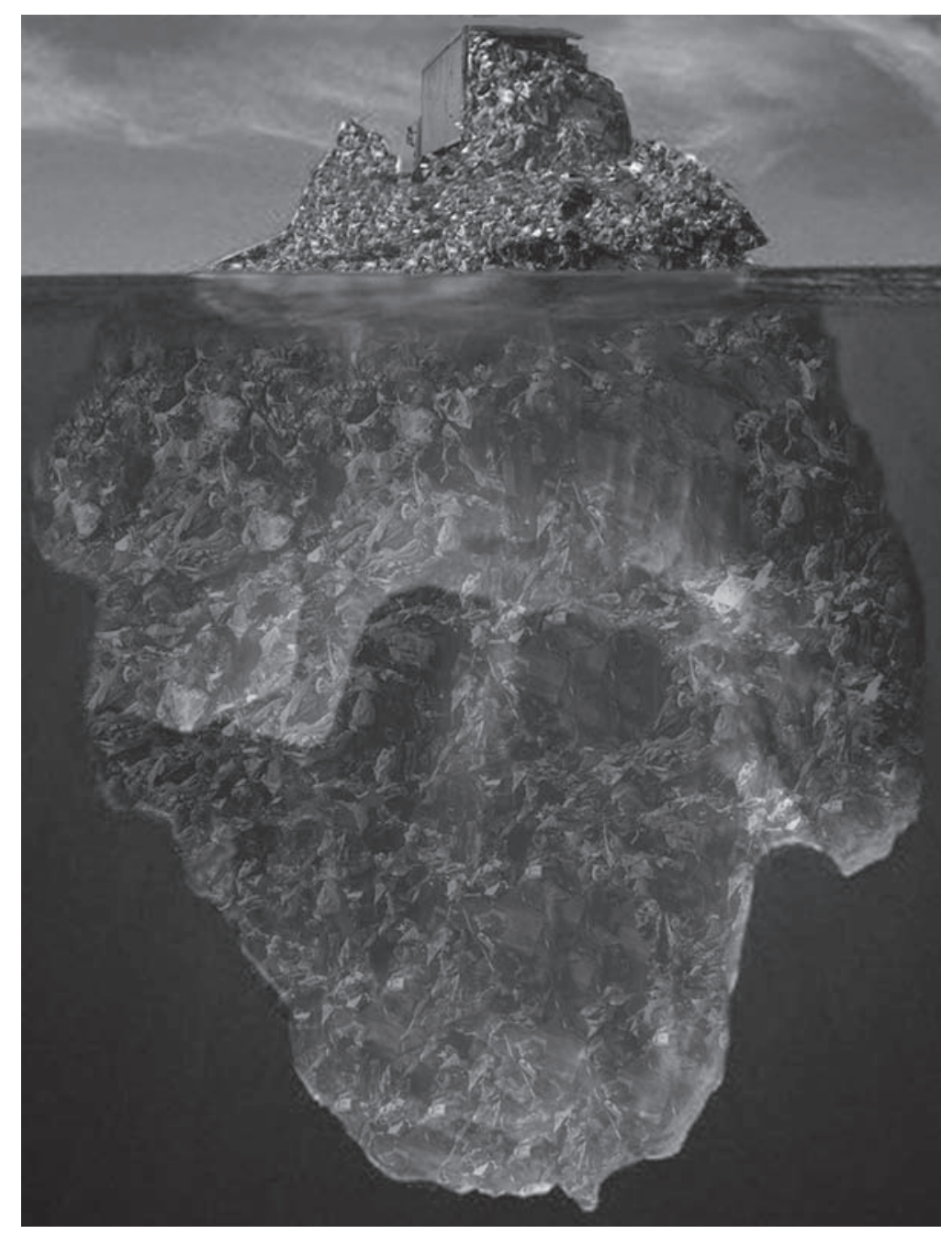

FOTO 1. Representación de un Iceberg de residuos. Fuente: Elaboración propia, 200933.

3 Imagen inspirada en la que presenta Cristina Cortinas de Nava, disponible en la página www.cristinacortinas.com. 


\section{Introducción}

Dentro de nuestras ciudades, que hace ya un par de años albergan a más de la mitad de la población mundial, uno de los problemas más graves es el de los residuos sólidos. Muchas veces la indiferencia que se asigna al tema impide notar el gran potencial que estos residuos albergan, en donde la materia procesada representa en sí misma un recurso desaprovechado. Cuando analizamos los asentamientos alrededor del globo, la gestión de residuos aparece crónicamente como uno de los rubros más relegados. Este hecho se repite sin importar el nivel de desarrollo o el lugar del emplazamiento. El almacenaje en forma de vertedero es exactamente el mismo desde la revolución industrial, en zonas muchas veces inadecuadas, excediendo frecuentemente la capacidad del sitio explotado. Hoy en día, con las reformas tecnológicas, jurídicas y sociales con las que contamos, no hay justificación para continuar alimentando un sistema obsoleto en el que se consienten las fuertes pérdidas de calidad de la materia procesada.

Dicho sistema obsoleto, utilizado por la mayoría de los gobiernos actuales, en lugar de reforzar los procesos productivos de los que dependemos, incrementan el peso sobre el ya sobrepasado ecosistema ${ }^{4}$.

Para comprender el peso de los residuos sobre el medio, se debe visualizar a nuestro planeta como un sistema confinado, en donde sólo los rayos solares inciden como variable externa a ser tomada en cuenta. El hombre, en su búsqueda de satisfacer la ley de la oferta y la demanda, explota cada vez más las materias primas y, debido a esto, el equilibrio "ecológico-económico" no llega nunca. Como bien explica el economista José Manuel Naredo: Los procesos físicos se ocultan bajo un velo monetario de la producción agregada de valor, y en un mundo finito, en el que estamos llevando los recursos de la biósfera al límite, es frustrante no poder expresar las inequidades que sufren los sistemas económicos naturales ${ }^{5}$ por la irrealidad que implica depender de un marco homogéneo de valor. Las unidades operativas a las que denominamos ciudades, son la forma más eficiente para reducir nuestro impacto, dotar de servicios y minimizar riesgos, pero incluso estas zonas urbanas necesitan una gran cantidad de territorio para operar eficientemente. 
En sólo 30 años la población mundial ha aumentado un $52 \%{ }^{6}$. En paralelo, la generación de desechos se ha duplicado ${ }^{7}$. Por sí mismas, estas cifras ya son alarmantes, no obstante, éstas se hacen mucho más significativas cuando entendemos que la evolución del consumo y el desecho no ha sido constante. La situación varía drásticamente cuando se analizan las distintas realidades económicas por región, encontrando un incremento en los niveles de generación de residuos de hasta un 300\% en el mundo desarrollado; superando de cinco a seis veces a los países en desarrollo ${ }^{8}$.

Las urbes más representativas para exponer el panorama actual, son sobre todo las ciudades de gran tamaño que por tener un mayor PIB $^{9}$ y dificultades de gestión, generan la mayor cantidad de residuos por habitante. Además que, por su extensión, complejidad, influencia y comunicaciones, son las destinadas a marcar el camino para el resto de su país. El presente artículo estudia las ciudades de París y Tokio, que han tenido notables avances en distintos aspectos de su gestión de residuos, México, como metrópolis de país en vías de desarrollo

6 De 4,406'347,000 personas el 1 de Julio de 1979 a 6,754'166,035 personas el 18 de marzo 2009 (UN, 2009).

7 De 6,000 millones de toneladas de residuos sólidos en los '70s a aproximadamente 12,700 millones de toneladas al año 2,000. Con una proyección que continúa con la misma tendencia (Tanaka, 2006).

8 UN, 2001; UN, 2009; Tanaka, 2006.

9 PIB o Producto Interno Bruto = consumo + inversión bruta + gastos gubernamentales + (exportaciones - importaciones). con nuevas herramientas jurídicas en proceso de aplicación, y Madrid, como la ciudad española que presenta las mayores similitudes jerárquicas, para fungir como muestra y equiparar los datos obtenidos de los distintos modelos analizados. Las cuatro cuentan con el rango de capital, el cual, sin ser determinante para estudiar los residuos generados, es un título que, principalmente en países en vías de industrialización, conlleva responsabilidades y resoluciones gubernamentales que sólo se pueden observar en estas localidades de mayor jerarquía.

La evaluación de la gestión de los residuos en territorios aislados es insuficiente, la única manera de llegar a soluciones globales es lograr que las ciudades homologuen sus instrumentos de análisis para poder compartir información y emprender un esfuerzo conjunto. Un ejemplo claro, es la red de información en el ámbito de los recursos y residuos que se ha conseguido parcialmente por las capitales asiáticas; el ANMC21 (Asian Network of Major Cities 21) es una red internacional con la finalidad de coordinar y dar a conocer proyectos y tareas comunes. 


\section{Sostenibilidad en el modelo económico actual}

“...cualquier experimento de laboratorio o cualquier proyecto de ciudad puede ser sostenible a plazos muy dilatados si se ponen a su servicio todos los recursos de la Tierra, sin embargo, muy pocos lo serían si su aplicación se extendiera a escala planetaria. Hablaremos, pues, de sostenibilidad global, cuando razonamos sobre la extensión a escala planetaria de los sistemas considerados, tomando la Tierra como escala de referencia y de sostenibilidad local cuando nos referimos a sistemas o procesos más parciales o limitados en el espacio y en el tiempo".

Naredo, 1996.

El modelo económico de estos tiempos contiene una seria carencia de índole especulativa, en la cual se separa tajantemente a los compradores del material cotizado. En esta dicotomía de mercado, cada elemento adquiere un peso propio, en donde los agentes que controlan los mercados son capaces de influir sobre las carencias y abundancias de los recursos, ignorando categóricamente la simetría del proceso. En este sentido, la insostenibilidad del modelo estriba en esta parcialidad de los parámetros de crecimiento, al asumir que existen recursos ilimitados en un mundo que cada vez cuenta con menos.

186 revista invi № 70 / Noviembre 2010 / Volumen № 25: 181-222
Es bajo este mismo modelo de desarrollo que los desperdicios ${ }^{10}$ se ven en función de su vida póstuma. Una vida que sin previsión alguna, obliga a asignarles funciones añadidas para las cuales los productos de consumo no fueron diseñados. No obstante, lidiar con las incongruencias de diseño para pensar en el futuro reciclaje de un producto es sólo un primer paso. El verdadero foco de atención se debe centrar en la filosofía, de consumo masivo que lleva al desperdicio masivo, que impera en estos tiempos, con el propósito último de llegar a parámetros lógicos de entropía. En donde se utilicen los recursos eficientemente; aprovechando su intercambio energético y se comprenda que "lo no aprovechado" es una manera poco crítica de decir que reforzamos un sistema en el que adquirimos cosas que no necesitamos.

\section{La basura en la ciudad}

Existen dos hipótesis que de manera conjunta esclarecen la notoria preferencia que existe por lo urbano en las sociedades contemporáneas ${ }^{11}$. La primera indica que las actividades primarias cada vez son más eficientes (pues menos de la mitad de la población abastece al resto). La segunda complementa la teoría indicando que son las ciudades las que cada vez consumen menos, reduciendo así su impacto.

10 La manera que tenemos más cercana a nombrar algo que no se ha aprovechado por completo.

11 UN, 2009. 
Aun cuando ambas hipótesis son congruentes, su comprobación es complicada. La realidad es que los individuos que habitan las ciudades consumen más energía, y a medida que la ciudad se industrializa esto incrementa. A su vez, cuando la ciudad adquiere funciones de otras regiones y se especializa (como en el caso de ciudades en países desarrollados), sufre una desindustrialización, de la cual debería, como consecuencia, reducirse el consumo energético. Sin embargo, esto nunca sucede. A pesar del alto consumo energético que caracteriza a las ciudades, éstas pueden ser eficientes cuando se comparan con asentamientos intermitentes que cuentan con los mismos servicios.

El agricultor, en la medida que "se civiliza" se vuelve cada vez menos autosuficiente ${ }^{12}$. Hace no tanto tiempo, tan sólo antes de la revolución industrial, las familias tenían huertos en sus casas, y las ciudades se sostenían dependiendo casi exclusivamente de sus alrededores y los productos confinados en éstos. La evolución de las urbes aleja los territorios productivos de los residenciales. Al ocurrir esto se incrementan las necesidades energéticas relacionadas a la movilidad y a las infraestructuras de transporte. En los periodos de guerra se puede analizar dicho fenómeno. En éstos, la población vulnerada sufre una regresión temporal en donde, debido al

12 Autosuficiente en el sentido, totalmente arbitrario, en que uno depende de menos factores (recursos y sistemas) para funcionar en sociedad y sobrevivir. riesgo que implica cada movimiento, resurgen las actividades primarias dentro de la ciudad y baja el consumo energético ${ }^{13}$.

En la distinción ciudad-campo tan característica desde Vitruvio, la ciudad surge como protección de las fuerzas de la naturaleza. Esta división, en la que la naturaleza es un enemigo y ataca al pobre hombre, ya no tiene sentido. Nuestra relación con el medio natural ha pasado a ser proteccionista y los nuevos hogares tienen necesidades básicas distintas ${ }^{14}$. En la cima de esta nueva jerarquía de necesidades, se coloca la protección en contra de la ciudad misma. La permanencia de la sociedad puede estar comprometida por la misma ciudad en aquellos casos en que el consumo y desperdicios de esta sociedad superan la capacidad de su medio $^{15}$. Especialmente en el momento que se sistematiza la introducción de elementos ajenos a la esfera renovable, que permiten explotar recursos muy por encima de su tasa de renovación y, a la vez, producir una gran cantidad de desechos imposibles de ser reintegrados de forma natural por el medio. Las nuevas tecnologías se incorporan a viviendas, buscando dar solución a los fenómenos urbanos en evolución constante. Hoy, la inseguridad, la falta de privacidad y los residuos (en forma de contaminación, ruido y malos olores), son in-

13 Girardet, 2001.

14 Fariña y Ruiz, 2002. Hernández Aja, 2009.

15 Fischer-Kowalski et al., 1997. 
convenientes que generan estrés, a la vez que fomentan el hermetismo y la vulnerabilidad social.

\section{Descripción de la economía de materiales}

"It is unlikely that the planet can accommodate an urbanized humanity which routinely draws resources from ever more distant hinterlands, or routinely uses the biosphere, the oceans and the atmosphere as a sink for its wastes".

Herbert Girardet, 1999.

Si analizásemos las tendencias de las últimas décadas, y fuésemos objetivos, podríamos llegar a la conclusión de que uno de los propósitos de la actividad económica es transformar la materia en residuos ${ }^{16}$. El gran incremento reflejado en el consumo sigue el mismo vector que el de los residuos. Esto quiere decir que los procesos biológicos del ser humano casi no han incrementado ${ }^{17}$. Sin embargo, el incremento en paralelo tiene otras implicaciones relevantes, puesto que, a pesar de los avances en reciclaje y manías por la conciencia ecológica, las industrias y también los individuos desechamos a la misma velocidad con la que adquirimos los productos.

16 Gardner et al, 1999.

17 Digo casi, porque la altura y el peso medio de la población se ha incrementado y, por consiguiente, el porcentaje de alimentos para solventarlo. Sin embargo, la diferencia en el consumo por factores alimenticios sigue siendo despreciable en los totales globales.
Por medio de la economía de materiales es posible definir el ciclo de vida de los productos dentro del marco económico, normalmente dividida en las fases de: Extracción, producción, distribución, consumo y descarte. El recurso se busca, se encuentra y se vende, hasta que ya no es requerido. Hasta mediados del siglo pasado, era suficiente pensar en un sistema como éste que funcionara linealmente. Las consecuencias de excavar lo requerido y deshacerse de lo indeseado aún estaban dentro de los límites de carga de la biosfera. El planeta era suficiente para completar el ciclo, y siempre que fuera necesario, sólo había que ir a otro territorio y volver a empezar.

El sistema lineal en un planeta con recursos finitos no puede operar indefinidamente. La permanencia de este sistema está en función de la durabilidad de los productos. Mientras más dura un teléfono, menos teléfonos tengo que adquirir en mi vida. Pese a la lógica absoluta de este argumento, esta visión dejó de tener sentido hace ya mucho tiempo. A pesar de esto, la importancia al valor agregado no sería un problema, si los instrumentos destinados a administrar los recursos, no fueran los mismos dedicados a revalorizar los productos. 

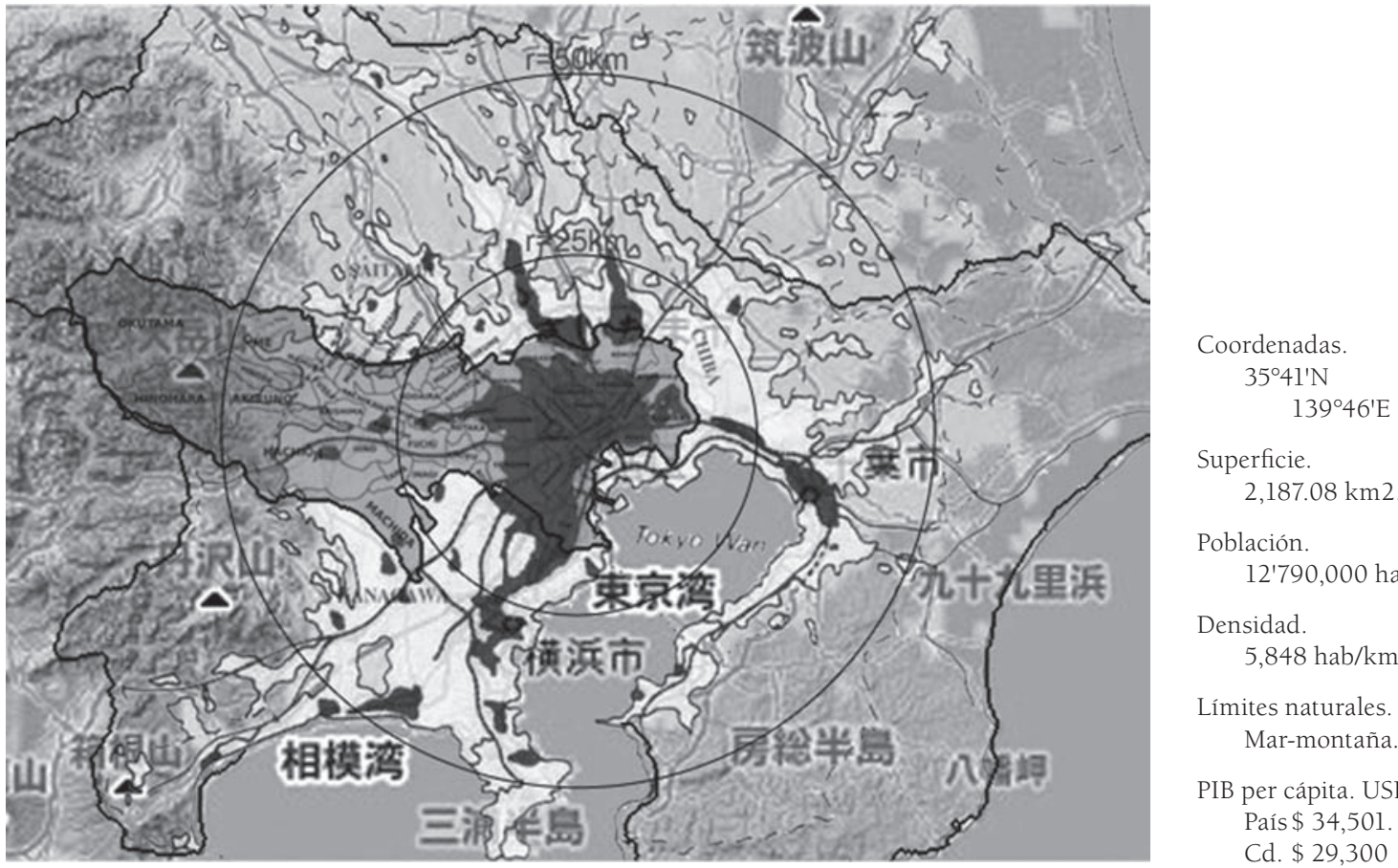

PIB per cápita. USD País \$ 34,501.

Cd. $\$ 29,300$

FIGURA 1. En gris claro la Prefectura de Tokio. Densidad: En Blanco superior a 500 hab/km2, en Negro superior a 5000hab/km2. Fuente: Elaboración propia a partir de datos de TMG, 2009, UN, 2006 y OECD, 2009.

\section{Las zonas de estudio}

\section{TOKIO}

La capital de Japón es, sin ninguna duda, una de las urbes más complejas de nuestro tiempo. Ubicada al sur de la región Kanto, al centro del archipiélago japonés. La megalópolis de Tokio o Greater Tokyo Area se conforma por 4 prefecturas que rodean la bahía de Tokio. Esta región alberga a más de una cuarta parte de la población de Japón y desde 1965 delimita a la megalópolis más poblada del mundo ${ }^{18}$.

18 UN, 2006. 
Nuestra área de estudio es la prefectura de Tokio, también considerada por el gobierno japonés como la prefectura metropolitana de Tokio -to-. Está delimitada al norte por la prefectura de Saitama, al este por el río Edo y la prefectura de Chiba, al oeste por las montañas y la prefectura de Yamanashi, y al sur por el río Tama y la prefectura de Kanagawa. Formalmente, la prefectura se divide en dos: el área central, que a su vez se divide en 23 barrios especiales - $k u$-, y el área poniente de Tama, conformada por 30 áreas administrativas menores (26 ciudades -shi-, 3 pueblos -machi- y una villa -mura- $)^{19}$.

A pesar de que la prefectura de Tokio contiene la parte más densa y poblada de la metrópoli, la mancha urbana se extiende sin reconocer delimitaciones administrativas. Como observamos en la imagen anterior y como sucede con todas nuestras áreas de estudio, la región en cuestión sólo engloba una parte de la ciudad. Esta unidad conceptual nos va a permitir comparar los datos generados directamente por las administraciones locales sin tener que explicar complicadas acepciones metodológicas que se traducirían en un tiempo y una extensión de la que no disponemos en el presente artículo. También nos libera de datos controvertidos como son la superficie urbanizada y sus correspondientes estimados de población que, incluso cuando provienen de una sola dependencia, suelen tener diferentes interpretaciones.

19 TMG, 2009

190 revista invi № 70 / Noviembre 2010 / Volumen № 25: 181-222
El pequeño apartado de Residuos de Manejo Especial, al fondo de la gráfica, corresponde a los residuos peligrosos que son recolectados por el sector que los genera. En este caso, al igual que Madrid y París, Tokio recibe los residuos farmacéuticos y hospitalarios en todas las farmacias de la prefectura para luego entregarlos a los servicios de recogida para su disposición final.

\section{PARÍS}

La capital de Francia está ubicada al centro de la región de Ile de France y es la única que se clasifica como Commune-Département (Municipio Comuna) por su pequeño tamaño. Renombrada también por ser el lugar más visitado del mundo y consolidar una de las economías más influyentes de Europa $^{20}$. La urbe de París toma forma a la vez que se aleja de los confines de su Departamento. La Zona Urbana se conoce como "El Gran París" e incluye a toda la Región de la Isla de Francia.

Por variables que influyen en el tipo de gestión de los Residuos Domiciliarios, se decidió reducir el área de estudio al Departamento de París junto con los tres departamentos que lo rodean, también conocidos como "Primera o Pequeña Corona". Los Departamentos son: Hauts de Seine, Seine Saint Denis y Val de Marne. Esta región está delimitada a su vez por 4 Departamentos, los cuales terminan

20 INSEE, 2009 


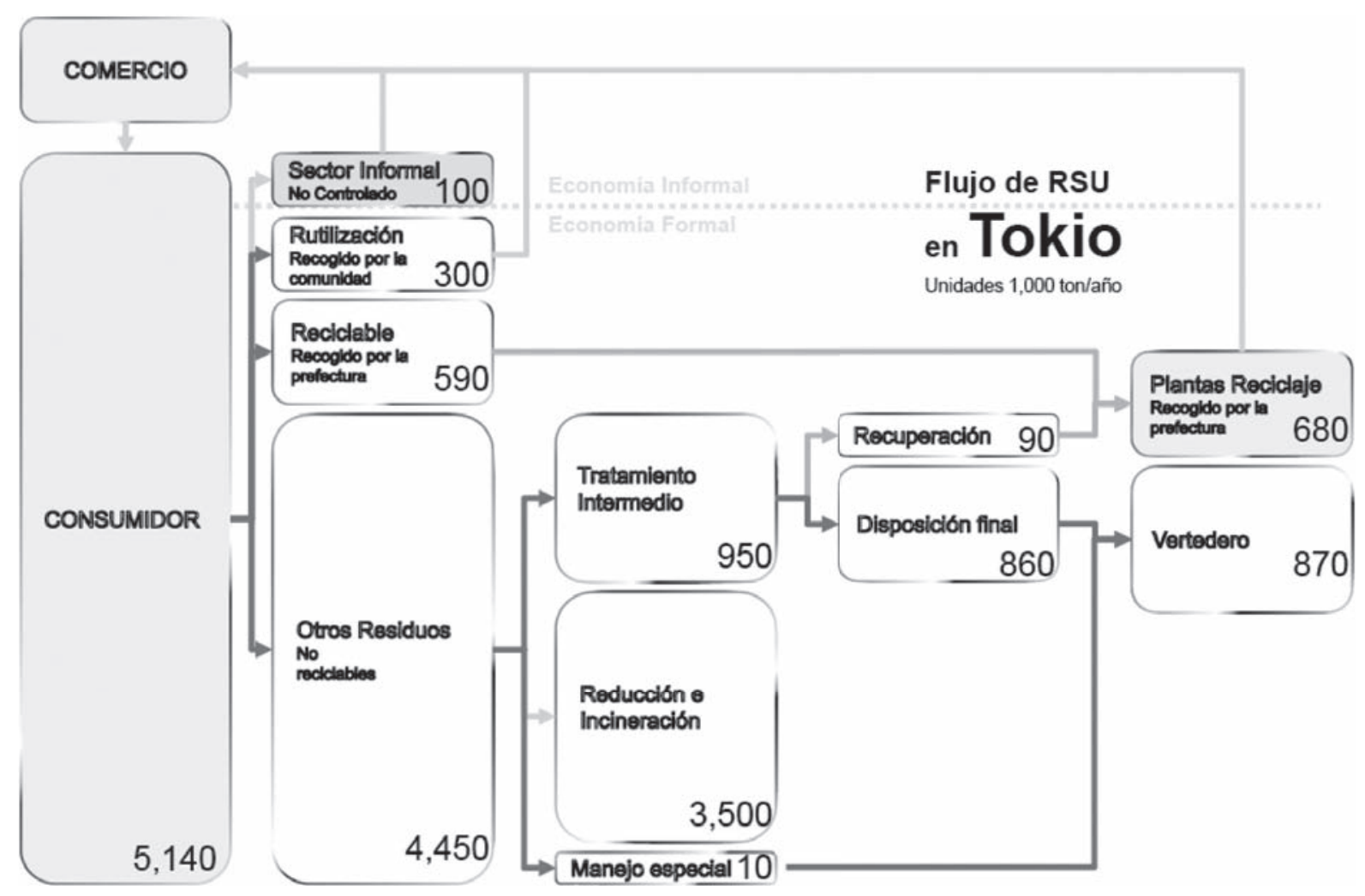

ESQUEMA 1. Flujo de residuos domiciliarios en la prefectura de Tokio. Año 2005. Fuente: Elaboración propia con datos de TMG, 2009. 

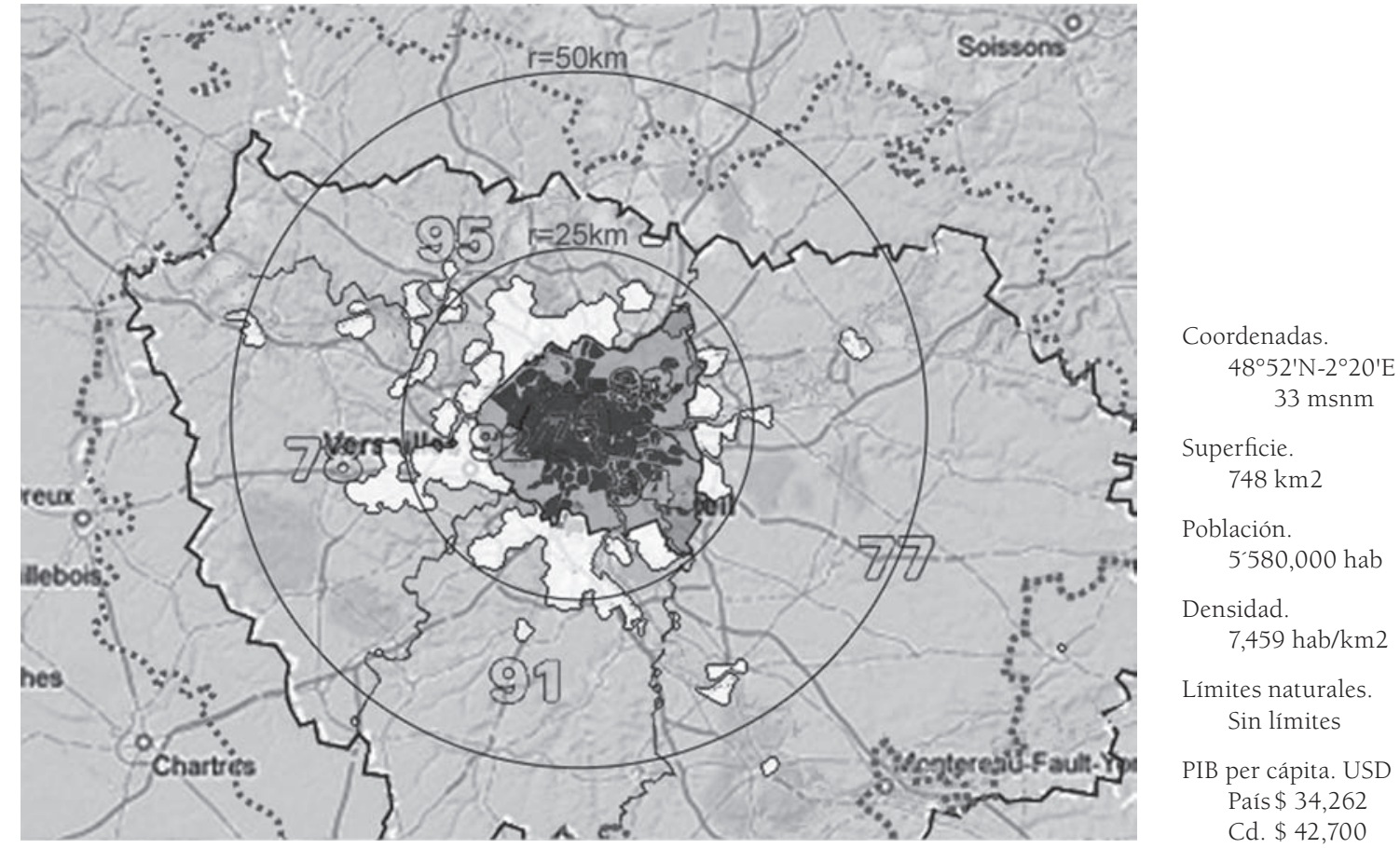

Límites naturales. Sin límites

PIB per cápita. USD País $\$ 34,262$ Cd. $\$ 42,700$

FIGURA 2. En gris claro París con su primera corona. Densidad: En Blanco superior a 500 hab/km2, en Negro superior a 5000hab/km2. Fuente: Elaboración propia a partir de: SYCTOM, 2005; PGP, 2006; OECD, 2009.

por englobar la Région Ile de France. Al norte por el departamento de Val d'Oise, al oriente por Seine et Marne, al sur por Essonne y al poniente por Yvelines. La gestión de Residuos Sólidos Domiciliarios de París es relativamente fácil de resumir. Casi todos los RD, debido a la lejanía de los vertederos, pasan por plantas de transferencia y de selección que aminoran en gran medida los desplazamientos totales. En la separación se da prioridad al reciclaje de envases y a la incineración, a la vez que el sector del compostaje pierde fuerza. Los vertederos son algo lejanos, en comparación con el promedio de las demás ciudades, sin embargo, están muy bien comunicados tanto por agua como por tierra. Y de 


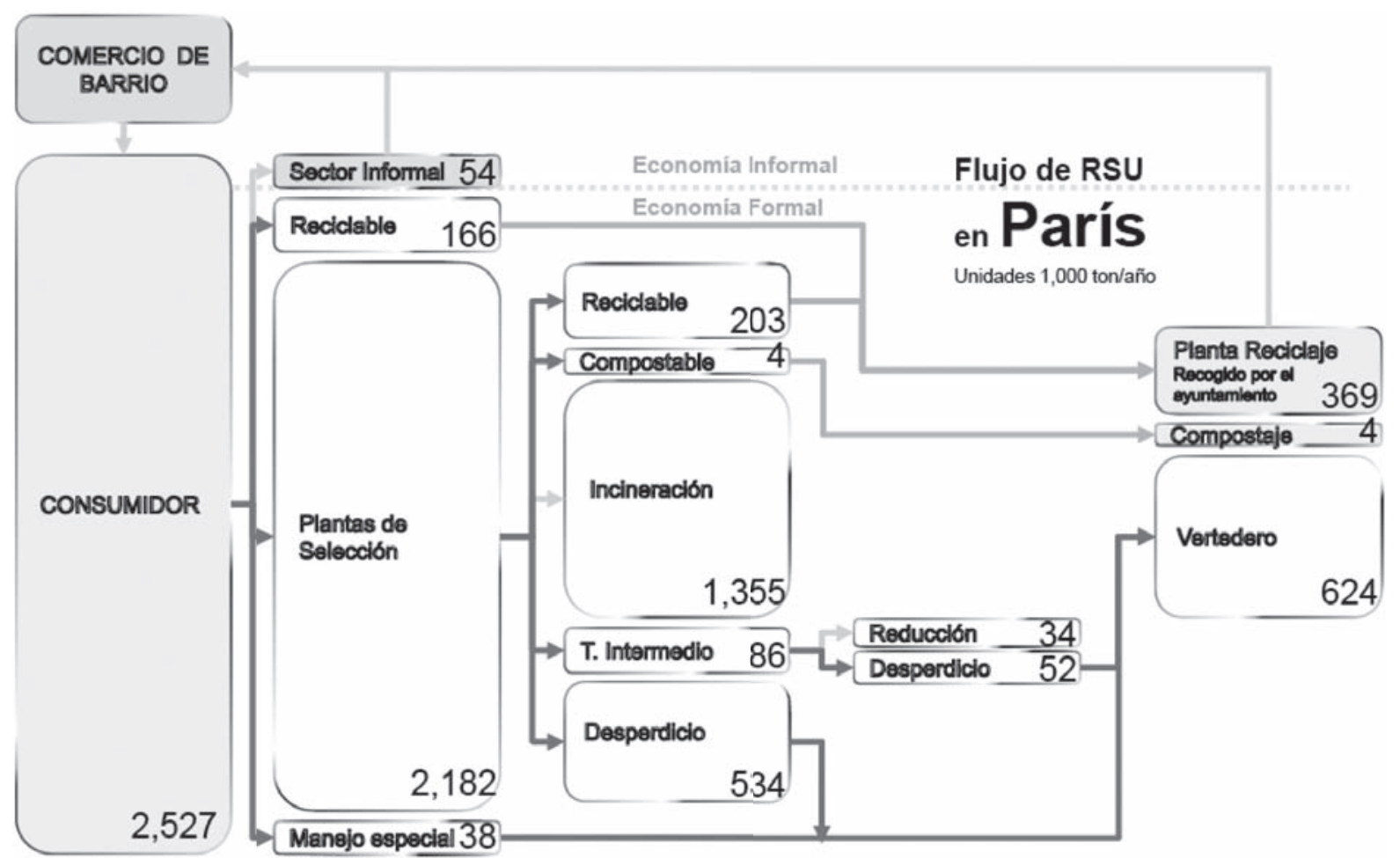

ESQUEMA 2. Flujo de residuos domiciliarios en París más primera corona. Los datos utilizados corresponden al año 2007. Fuente: Elaboración propia con datos de SYCTOM, 2006; PGP, 2009 
continuar las medidas de reducción en la generación y de recuperación energética, seguirán siendo suficientes para las siguientes dos décadas ${ }^{21}$.

\section{MADRID}

La ciudad capital de España, de la Comunidad y de la Provincia de Madrid, es una de las metrópolis más grandes de Europa. Sin tener el rango de megalópolis ${ }^{22}$, a diferencia de las demás ciudades examinadas, sigue siendo el centro logístico y de información del país. Se ubica al centro de la Comunidad Autónoma de Madrid, la cual se circunscribe entre las provincias de Castilla y León (Segovia y Ávila) al Nor-Oeste y Castilla-La Mancha (Cuenca, Toledo y Guadalajara) al Sur y Nor-Este; al centro de la Península Ibérica.

El área de estudio se determinó en base a los datos obtenidos del gobierno de la ciudad, fundamentados en la cuantificación de residuos por destino final. En el caso de Madrid, el Vertedero de Rivas-Vaciamadrid es el responsable de gestionar los residuos del Ayuntamiento, su municipio y el municipio que los articula (Araganda del Rey). La inclusión de ambos municipios disminuye sólo un

\footnotetext{
21 ORDIF, 2009.

22 Su área metropolitana no sobrepasa los 10’000,000 de habitantes.
}

194 revista invi № 70 / Noviembre 2010 / Volumen Nº 25: 181-222 poco la densidad poblacional, que permanece por debajo de la Prefectura de Tokio.

El esquema es el mismo que el de París, con significativas diferencias en materia de recuperación, compostaje e incineración.

\section{MÉXICO}

La capital de la República Mexicana es una de las ciudades más pobladas ${ }^{23}$ y socialmente más polarizadas del mundo. Ciudad que, a diferencia de las 3 anteriores, se encuentra en un país en vías de desarrollo y presenta factores cualitativa y cuantitativamente distintos. La Ciudad de México se ubica al centro de la cuenca del Valle del mismo nombre, y confinada por la Zona Metropolitana del Valle de México $(Z M V M)^{24}$. Se extiende en una de las zonas tectónicas más complejas, al oriente del Eje Neovolcánico, con elevaciones desde los 2,240 msnm hasta los 5,452 msnm en el Popocatépetl (SMN, 2008).

Se tomó como área de estudio el Distrito Federal que, por los mismos motivos que la prefectura de Tokio (datos de población y residuos), es la más adecuada para la investigación. El DF abarca las partes de mayor densidad de la ciudad en paralelo a las zonas ru-

23 De acuerdo con la ONU, México es la ciudad más poblada después de Tokio y seguida de cerca por Nueva York, Sao Paulo y Bombay (UN, 2009; UN, 2006).

24 Zona Metropolitana del Valle de México (ZMVM) formada por las 16 delegaciones del DF y 58 municipios conurbados (GDF, 2009). 


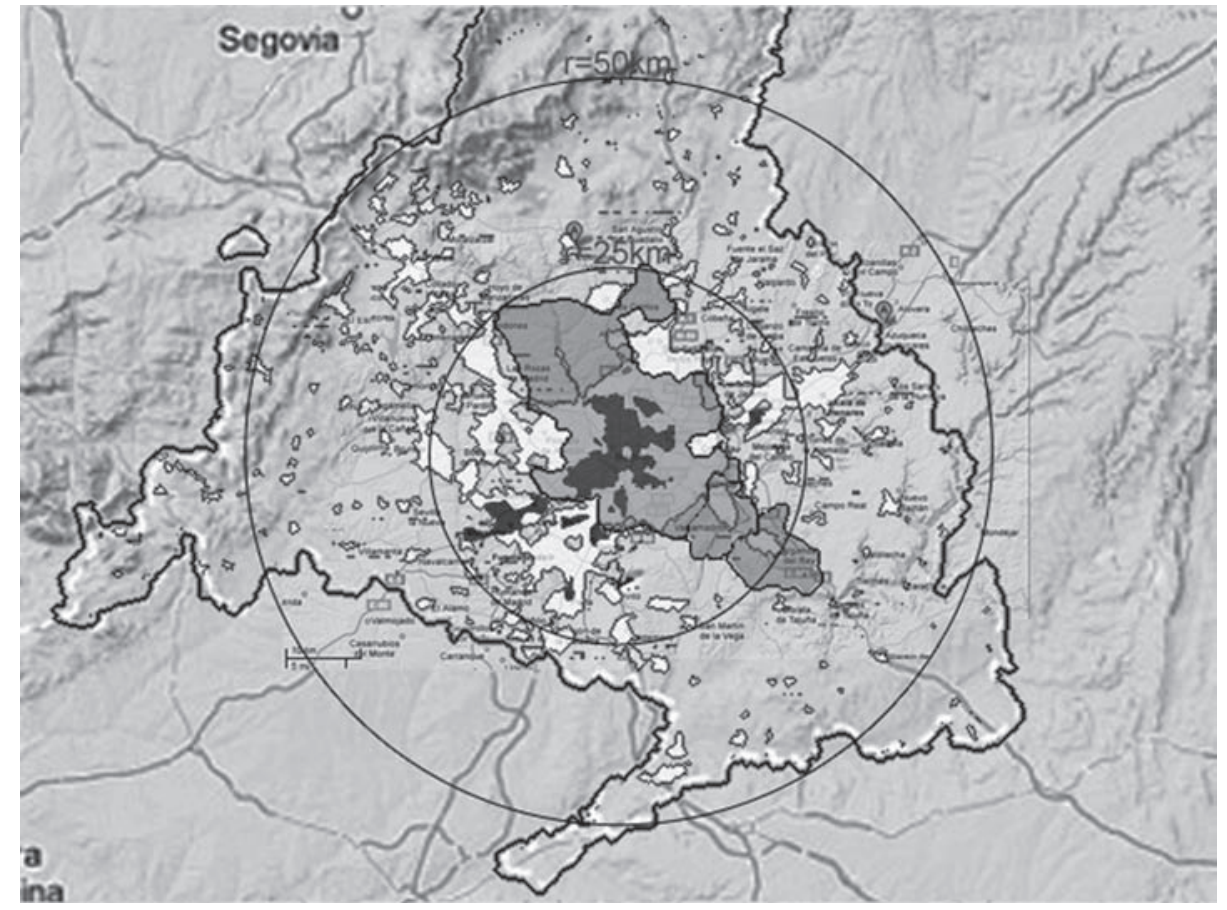

Coordenadas $40^{\circ} 24^{\prime} \mathrm{N}-3^{\circ} 4 \mathrm{l}^{\prime} \mathrm{O}$ $667 \mathrm{msnm}$

Superficie.

$606 \mathrm{~km} 2$

Población 3'242,703 hab

Densidad.

5,353 hab/km2

Límites naturales. No inmediatos.

PIB per cápita. USD País \$ 30,757 Cd $\$ 29,000$

FIGURA 3. En gris claro el Ayuntamiento de Madrid. Incluyendo los municipios de Arganda del Rey y Rivas-Vaciamadrid. Densidad: En Blanco superior a 500 hab/km2, en Negro superior a 5000hab/km2. Fuente: Elaboración propia a partir de: BOE, 2009; CM, 2006; OECD, 2009.

rales y bosques. Se encuentra delimitada al sur por el Estado de Morelos y el resto por el Estado de México. Una peculiaridad que tiene la Ciudad de México es que, al igual que París, tiene un PIB muy superior a la media del país que, junto a su enorme número de habitantes, la ubica en el octavo puesto a nivel mundial. Sólo después de Tokio, Nueva York, Los Ángeles, Chicago, París, Londres y Osaka/Kobe ${ }^{25}$. La gestión de residuos de México DF es un ámbito complejo de analizar: En el sector formal, por

25 UKEO, 2007 


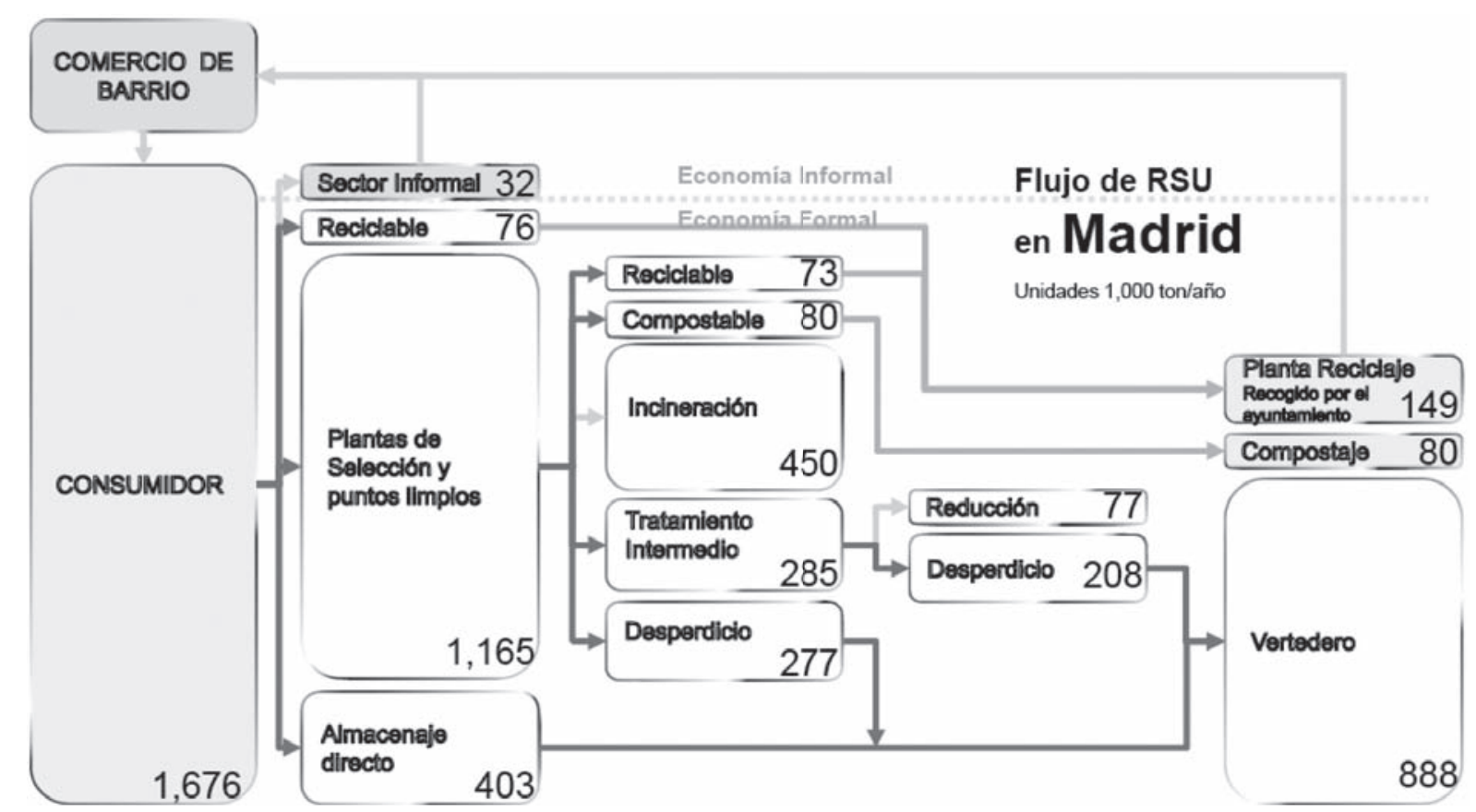

ESQUEMA 3. Flujo de residuos domiciliarios en el ayuntamiento de Madrid. Los datos utilizados corresponden al año 2004. Fuente: Elaboración propia con datos de CM, 2009.

cuestiones de tiempo y también de costumbre, los residuos no se separan en fuente. La lejanía relativa del vertedero y el mal estado de algunos equipos (especialmente los camiones recolectores), obligan a que los residuos pasen por Depósitos Temporales o
Centros de Transferencia, en donde se introducen en tráileres de 20 toneladas que trasladan los desechos a las 3 plantas de separación que existen en el DF. Una vez separado lo más útil, se vuelven a transportar los residuos al único vertedero de la ciudad ${ }^{26}$.

26 GDF, 2009; JICA, 1999 


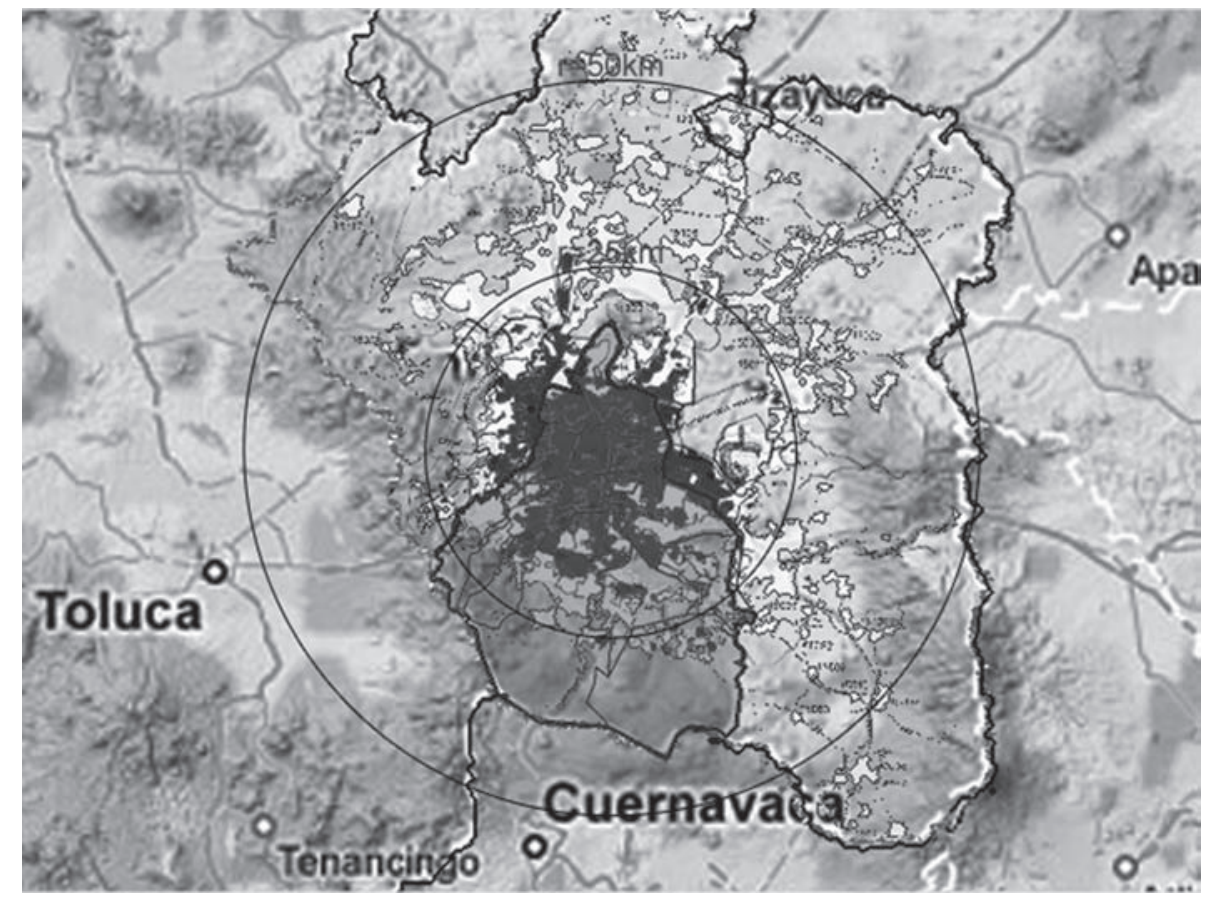
Coordenadas. $19^{\circ} 25^{\prime} \mathrm{N}-99^{\circ} 07^{\prime} \mathrm{O}$ $2,240 \mathrm{msnm}$

Superficie.

$1,486 \mathrm{~km} 2$

\section{Población.}

$8^{\prime} 836,045$ hab

Densidad.

5,946 hab/km2

Límites naturales.

Montañas

PIB per cápita. USD País $\$ 14,582$

Cd. $\$ 19,810^{*}$

FIGURA 4. En gris claro México D.F. Densidad: En Blanco superior a 500 hab/km2, en Negro superior a 5000hab/km2. Fuente: Elaboración propia a partir de: INEGI, 2007* y 2008; GDF, 2009; OECD, 2009.

El sector informal se solapa al anterior. Los barrenderos, carretoneros y ropavejeros ${ }^{27}$ venden los materiales y objetos valorables de las casas y áreas públicas, los ayudantes o peones seleccionan lo

27 Carretoneros y Ropavejero son términos que equivalen al de trapero o chamarilero de otros países. Personas que dependen de la recuperación del valor de los objetos abandonados desde el ámbito informal. que pueden del servicio de colecta a bordo de los camiones, y los pepenadores lo hacen en el resto del proceso, ya sea a través de mafias o familias que viven del resultado de la búsqueda. 


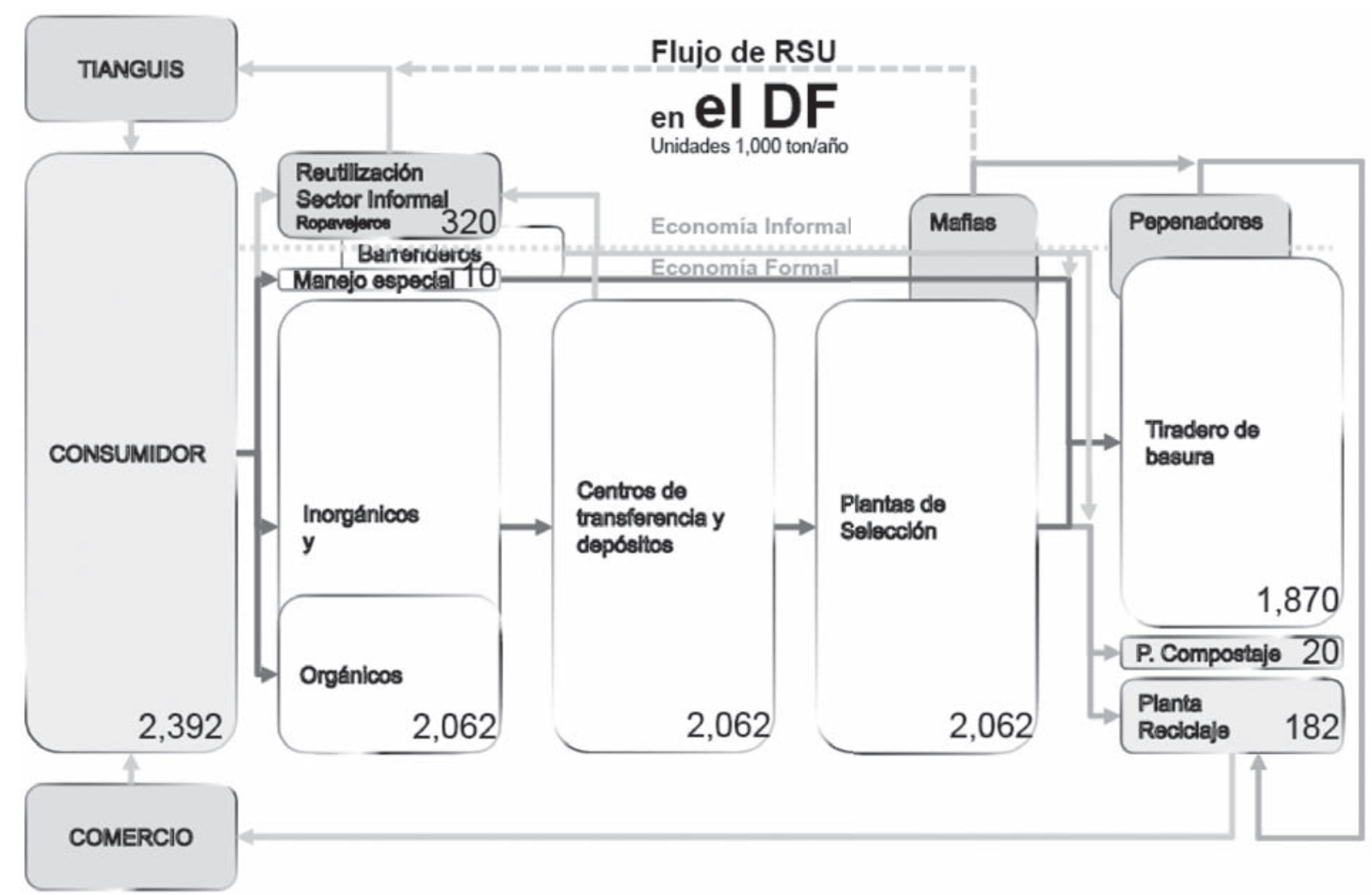

ESQUEMA 4. Flujo de residuos domiciliarios en el Distrito Federal. Los datos utilizados corresponden al año 2004, por lo cual la aplicación de la recogida selectiva (orgánico/inorgánico) aún no es efectiva. Fuente: Elaboración propia con datos de INE, 2009; GDF, 2009. 


\section{Comparación y clasificación}

Empezando por los valores totales de generación, en la siguiente gráfica se interpretan los datos cuantificados por ciudad. Como se observa, las diferencias son mucho mayores en los procesos industriales. Recordando que no se incluyen los RI informales y clandestinos, no cuantificados en el caso del DF.

TABLA 1: TABLA DE DATOS SELECCIONADOS POR CIUDAD

$\begin{array}{llllll} & \text { TOKIO } & \text { PARIS } & \text { MADRID } & \text { MEXICO } \\ \text { Área de Estudio } & \text { Prefectura de Tokio } & \text { París + Primera Corona } & \text { Ayuntamiento + 2 municipios } & \text { Distrito Federal } \\ \text { Superficie Estimada km2 } & 2,187.08 & 748.00 & 605.79 & 1,486.00 & \\ \text { Población } & 12,790,000 & 5,580,000 & 3,242,703 & 5,836,045 & 5,946.19 \\ \text { Densidad hab/km2 } & 5,847.98 & 7,459.89 & 5,352.85 & \text { INEGI }\end{array}$

TABLA 2: TABLA DE DATOS SELECCIONADOS POR CIUDAD

\begin{tabular}{|c|c|c|c|c|c|c|c|c|}
\hline & TOKIO & & PARIS & & MADRID & & MÉXICO & \\
\hline RESIDUO HABITACIONAL & 1,000 ton & 05 & 1,000 ton & 07 & 1,000 ton & 04 & 1,000 ton & 04 \\
\hline Recolección Directa & 300 & $6.0 \%$ & 54 & $2.2 \%$ & 32 & $1.9 \%$ & 320 & $15.4 \%$ \\
\hline Recolección total & 5,040 & $100 \%$ & 2,473 & $100 \%$ & 1,644 & $100 \%$ & 2,072 & $100 \%$ \\
\hline Almacenaje directo & 10 & $0 \%$ & 38 & $2 \%$ & 403 & $25 \%$ & 10 & $0 \%$ \\
\hline Reciclaje directo & 590 & $12 \%$ & 166 & $7 \%$ & 76 & $5 \%$ & - & $0 \%$ \\
\hline Plantas de Selección & 0 & $0 \%$ & 2,182 & $88 \%$ & 1,165 & $71 \%$ & 2,062 & $100 \%$ \\
\hline Composta & - & & 4 & & 80 & & 20 & \\
\hline Reciclaje & 90 & & 203 & & 73 & & 182 & \\
\hline Otros (incineración) & - & & 1,355 & & 450 & & - & \\
\hline Tratamientos & 4,440 & $88 \%$ & 86 & $3 \%$ & 285 & $17 \%$ & 0 & $0 \%$ \\
\hline Incineración & 2 & & 59 & & 77 & & - & \\
\hline Reducción & 4,438 & & 27 & & - & & - & \\
\hline Producto reciclado & 90 & $2 \%$ & 203 & $8 \%$ & 73 & $4 \%$ & 182 & $9 \%$ \\
\hline Producto almacenado & 860 & $17 \%$ & 624 & $25 \%$ & 485 & $29 \%$ & 1,860 & $90 \%$ \\
\hline Total reciclado & 680 & $13 \%$ & 369 & $15 \%$ & 149 & $9 \%$ & 182 & $9 \%$ \\
\hline Total compostaje & 0 & $0 \%$ & 4 & $0 \%$ & 80 & $5 \%$ & 20 & $1 \%$ \\
\hline Total en depósitos & 870 & $17 \%$ & 662 & $27 \%$ & 888 & $54 \%$ & 1,870 & $90 \%$ \\
\hline
\end{tabular}




\begin{tabular}{|c|c|c|c|c|c|c|c|c|}
\hline RESIDUO INDUSTRIAL & & 04 & & '04 & & ’05 & & 07 \\
\hline Recolección total & 22,410 & $100 \%$ & 12,690 & $100 \%$ & 5,801 & $100 \%$ & 2,428 & $100 \%$ \\
\hline Almacenaje directo & 400 & $2 \%$ & 7941 & $63 \%$ & 2751 & $47 \%$ & 1769 & $73 \%$ \\
\hline Reciclaje directo & 100 & $0 \%$ & 400 & $3 \%$ & 48 & $1 \%$ & 523 & $22 \%$ \\
\hline Compostaje directo & - & $0 \%$ & - & $0 \%$ & - & $0 \%$ & 29 & $1 \%$ \\
\hline Plantas de Selección & - & $0 \%$ & 1809 & $14 \%$ & 30 & $1 \%$ & 81 & $3 \%$ \\
\hline Reciclaje & - & & 263 & & - & & - & \\
\hline Tratamientos & 21,910 & $98 \%$ & 301 & $2 \%$ & 150 & $3 \%$ & 26 & $1 \%$ \\
\hline Infecciosos & - & & - & & 46 & & 26 & $\mathrm{t}+3$ \\
\hline Tratamientos & 7,040 & & 301 & & 75 & & - & \\
\hline Reducción & 14,870 & & 2,638 & & 75 & & - & \\
\hline Producto reciclado & 5,860 & $26 \%$ & 263 & $2 \%$ & 66.24 & $1 \%$ & 0 & $0 \%$ \\
\hline Producto almacenado & 1,170 & $5 \%$ & 2111 & $17 \%$ & 2,416 & $42 \%$ & 110 & $5 \%$ \\
\hline Total reciclado & 5,960 & $27 \%$ & 663 & $5 \%$ & 114 & $2 \%$ & 523 & $22 \%$ \\
\hline Total compostaje & 0 & $0 \%$ & 0 & $0 \%$ & 16 & $0 \%$ & 29 & $1 \%$ \\
\hline Total en depósitos & 1,570 & $7 \%$ & 10,052 & $79 \%$ & 5,166 & $89 \%$ & 1,879 & $77 \%$ \\
\hline $\begin{array}{l}\text { DEPÓSITOS CLANDESTINOS } \\
\text { TOTALES }\end{array}$ & 172 & & 100 & & 50 & & 19 & \\
\hline Generación & 27,622 & $100 \%$ & 15,263 & $100 \%$ & 7,495 & $100 \%$ & 4,519 & $100 \%$ \\
\hline Reciclaje & 6,640 & $24 \%$ & 1,032 & $7 \%$ & 264 & $4 \%$ & 705 & $16 \%$ \\
\hline Composta & 0 & $0 \%$ & 4 & $0 \%$ & 96 & $1 \%$ & 49 & $1 \%$ \\
\hline Almacenaje & 2,440 & $9 \%$ & 10,714 & $70 \%$ & 6,055 & $81 \%$ & 3,749 & $83 \%$ \\
\hline Clandestino & 172 & $1 \%$ & 100 & $1 \%$ & 50 & $1 \%$ & 119 & $3 \%$ \\
\hline Informal Doméstico & 30 & $0.6 \%$ & 20 & $0.8 \%$ & 30 & $1.8 \%$ & 160 & $7.7 \%$ \\
\hline Informal Industrial & 20 & $0.4 \%$ & 150 & $6.1 \%$ & 75 & $4.6 \%$ & 114 & $5.5 \%$ \\
\hline
\end{tabular}

FUENTE: Múltiples fuentes y cálculos aislados; consultar Bibliografía. 
Generación de Residuos Industriales por habitante por dia. unidaoss: Kø (RD) Residuos Domiclliarios: Verde Reutilzachón.

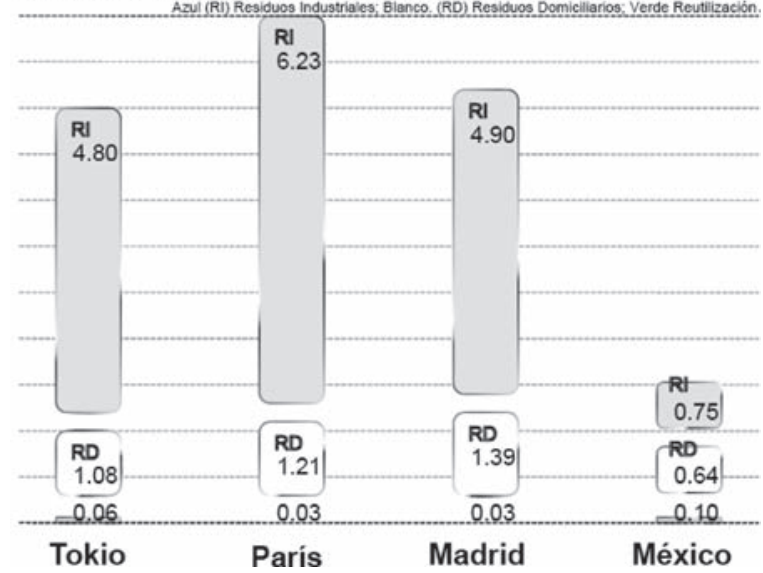

GRÁFICO 1. Fuente: Elaboración propia (datos: Tablas 1 y 2).

A partir de estas dos tablas, se obtuvieron los valores per cápita que se revisaron en la comparación de ciudades.

A diferencia de los $\mathrm{RD}$, en donde la generación de basura se sujeta a legislaciones y tipos de gestión con cambios sutiles, las diferencias de producción y consumo en la industria de un país son mucho más evidentes. La incidencia que tiene la industria en los residuos, cuando se revisa categóricamente, prevalece ante los aspectos económicos y sociales de cada población. Las diferencias son tan contundentes que, a pesar que la extracción de datos se base en fuentes gubernamentales con
Generación de Residuos Industriales por habitante por dia. Unidades: $\mathrm{K}_{0}$

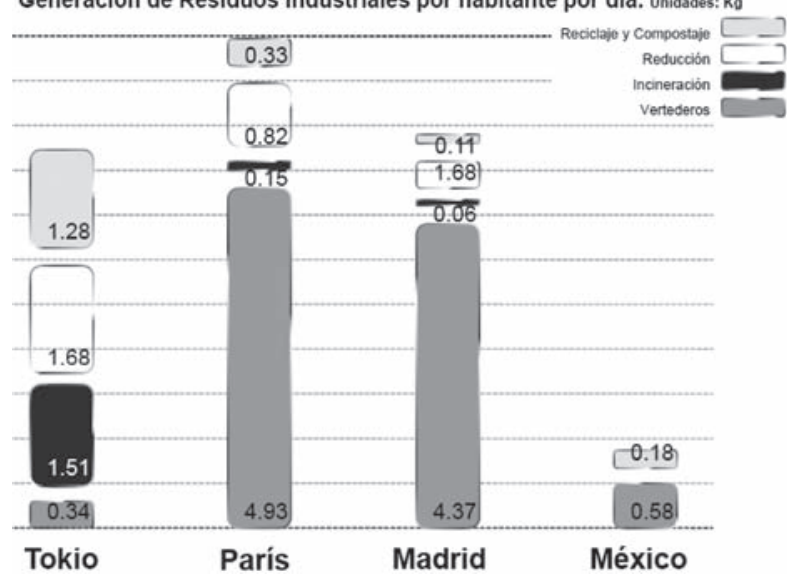

GRÁFICO 2. Fuente: Elaboración propia (datos: Tablas 1 y 2).

metodologías distintas, resultan difíciles de ignorar.

Los valores más destacados son los de material inerte o residuos de la construcción y demolición que, exceptuando Tokio, representan más de la mitad de los RI de la ciudad. Tokio es capaz de reducir significativamente sus residuos porque la mitad son lodos derivados de la industria que, con agentes químicos, biológicos y procesos de adsorción, purifica el agua para ser reincorporada en los ciclos productivos de la ciudad. Este éxito tiene mucho que ver con el hecho de que el $98 \%$ de sus residuos pase por algún tipo de Tratamiento Inter- 
medio con la única finalidad de extraer todo lo útil y dejar lo menos posible para almacenar. México D.F. es un caso opuesto en toda la lógica de gestión, basado prácticamente en un magno esfuerzo por que los equipamientos y equipo de recolección sean suficientes. En esta ciudad ocurre un fenómeno en el que la industria, siguiendo una lógica de beneficios económicos ${ }^{28}$, recupera y recicla la materia prima antes de que ésta abandone las fábricas que la desecharon.

Por otro lado, con los RD sí se pueden definir algunos patrones. El habitante de las ciudades industrializadas genera prácticamente el doble que el habitante promedio del DF. Sin embargo, la tasa de reutilización sigue una regla a la inversa, en donde el menor generador es también el que más reutiliza. El reciclaje en las cuatro ciudades es acorde a la cantidad de residuos, aunque en todas las ciudades sigue por debajo de su potencial, en función de la composición y las regulaciones vigentes.
Generación de Residuos Domiciliarios por habitante por dia. Unidades: Ka

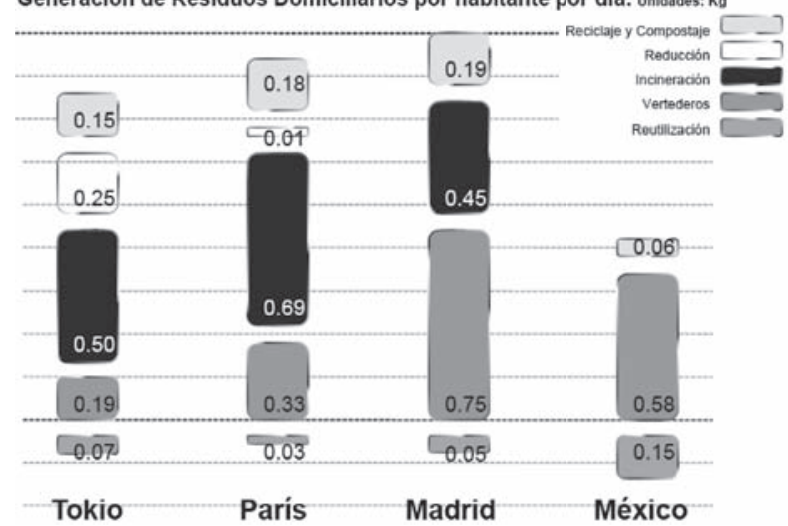

GRÁFICO 3. Fuente: Elaboración propia (datos: Tablas 1 y 2)

Un punto que cabe destacar, es que la ciudad de Madrid, con un PIB per cápita inferior a París y Tokio, genera más RD por habitante que las demás. En Tokio se puede explicar con el seguimiento de sus rígidas normativas impuestas desde hace más de 30 años, no obstante, París es un enigma. Es cierto que las políticas del SYCTOM han logrado mejoras cró-

28 Lógica de beneficios económicos en donde el precio reducido de materias primas desechadas es una manera de ser más competitivo en un país con mano de obra barata. A pesar de tener una visión distinta a los países desarrollados, esta tendencia se traduce también en mayor sostenibilidad. 
nicas en materia de control y reducción de residuos a partir del año 2001, mientras que la CM no ha conseguido frenar el incremento indiscriminado de residuos. Pero aún así, los valores pueden y deben ser cuestionados en ensayos posteriores, en donde la evolución de los residuos sea sometida a una crítica metodológica mucho más contundente.

La incineración, como se comentó en un principio, es una opción cuya popularidad sigue repuntando. Cada gobierno asume una postura que intenta justificar su posición en el tema. Tokio por falta de espacio, París y Madrid por invertir en energías alternativas y México por motivos más políticos que ambientales. Al revisar la composición de los $\mathrm{RD}$, se entiende que las diferencias son mucho más sutiles que los datos de gestión. Un poco más o menos procesado, después de todo, todos consumimos lo mismo.

Las mayores diferencias en materia desechada se dan en torno a tres conceptos: Celulosas (papel y cartón), plásticos y materia orgánica. Estas clasificaciones reflejan el grado de industrialización de la ciudad en relación a la materia procesada, o desde el punto de vista socio-económico, la vulnerabilidad de la población servida. Encontrando que la ciudad con mayor porcentaje de residuos orgánicos es la que menos procesa los productos e inversamente proporcional a los empaques, envases y embalajes de plástico, cartón y papel desechados. En donde la sociedad que ha alcanzado un mayor nivel adquisitivo, compra una menor cantidad de productos perecederos, y empaques más elaborados.

Cabe destacar que en México y París aparece el concepto de "finos"; contenido de distintos materiales de menos de $6 \mathrm{~cm}$ que ayuda a explicar un porcentaje no definido del contenido de la basura.

La siguiente tabla (Tabla 4) retoma algunas formas de gestión, generalizando la clasificación de los materiales. Por ejemplo, en el caso de Madrid, no todos los plásticos entran dentro de la categoría de "Envases". Existe una parte, de menor peso, que forma parte de los residuos electrónicos, vehiculares, peligrosos, voluminosos y restos. La cruz o "X" representa el tipo de producto que, cuando se recupera en alguna de las etapas de gestión, tiene un valor de recirculación y/o transformación en la industria de la ciudad.

Sin tener mucho que ver con el valor de intercambio que se le asigna a los bienes reciclados, la industria de la reutilización invierte los resultados anteriores. El alto contenido de materia orgánica aunado a una baja generación total de RD, normalmente se traduce en una alta tasa de reutilización. Ambas variables nos hablan de un territorio con menos desperdicio en el que se da prioridad a alargar lo más posible la vida de los productos.

En este caso, el DF es el que reutiliza una mayor parte de los bienes abandonados per cápita. Tanto 


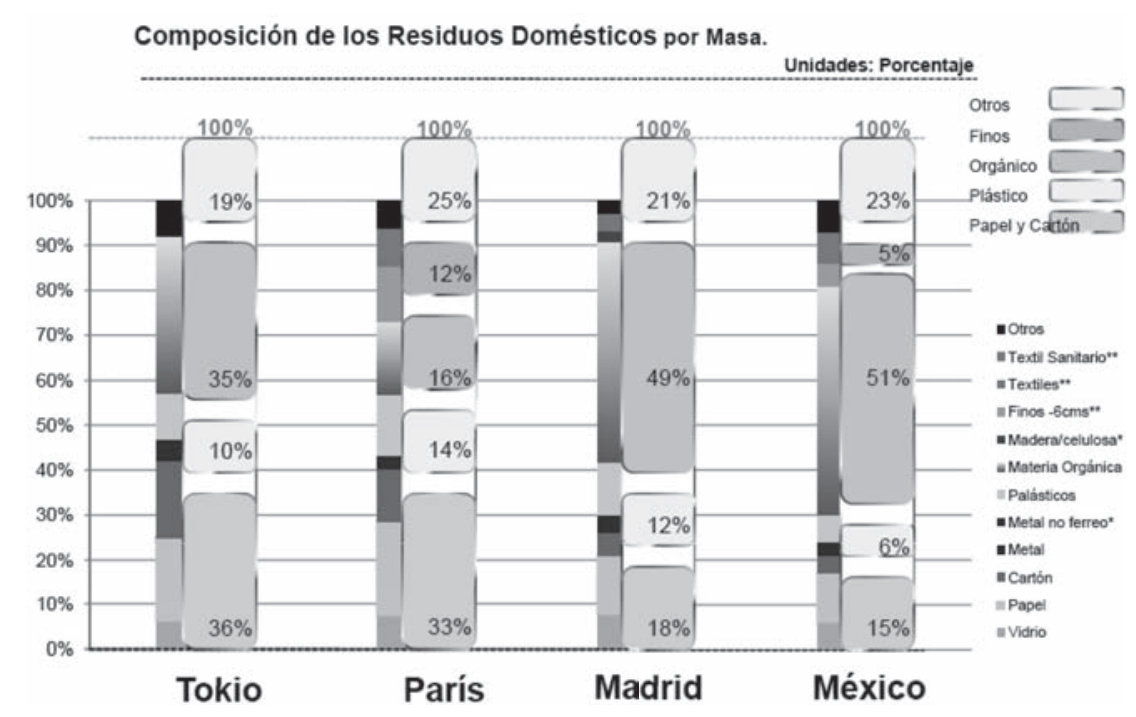

GRÁFICO 4. Fuente: Elaboración propia, a partir de los datos de la Tabla 3.

TABLA 3. COMPARACIÓN DE LAS 4 CIUDADES POR CANTIDAD DE COMPOSICIÓN DE RESIDUOS DOMICILIARIOS.

\begin{tabular}{lllll}
\hline Composición & TOKIO & PARIS & MADRID & MEXICO \\
\hline Vidrio & $6 \%$ & $7 \%$ & $8 \%$ & $6 \%$ \\
\hline Papel & $19 \%$ & $21 \%$ & $13 \%$ & $11 \%$ \\
\hline Cartón & $17 \%$ & $12 \%$ & $5 \%$ & $4 \%$ \\
\hline Metal & $5 \%$ & $3 \%$ & $3 \%$ & $3 \%$ \\
\hline Metal no férreo & - & - & $2 \%$ & - \\
\hline Plásticos & $10 \%$ & $14 \%$ & $12 \%$ & $6 \%$ \\
\hline Materia Orgánica & $35 \%$ & $16 \%$ & $49 \%$ & $51 \%$ \\
\hline Madera/celulosa & - & - & $3 \%$ & - \\
\hline Finos -6cms & - & $12 \%$ & - & $5 \%$ \\
\hline Textiles & - & $2 \%$ & $4 \%$ & $2 \%$ \\
\hline Textil Sanitario & - & $7 \%$ & - & $5 \%$ \\
\hline Otros & $8 \%$ & $6 \%$ & $3 \%$ & $7 \%$ \\
\hline
\end{tabular}

FUENTE: Elaboración propia. Múltiples fuentes. 
TABLA 4. COMPARACIÓN DE LAS 4 CIUDADES POR LA CLASIFICACIÓN GENERAL DE LOS RESIDUOS DOMICILIARIOS

\begin{tabular}{|c|c|c|c|c|c|c|c|c|}
\hline Composición & TOKIO & & PARÍS & & MADRID & & MÉXICO & \\
\hline Vidrio & No Combust. & $X$ & Selectos & $X$ & Selectiva & $X$ & Inorgánico & $X$ \\
\hline Papel & Combustible & $X$ & Selectos & $X$ & Selectiva & $X$ & Orgánico & $x$ \\
\hline Cartón & Combustible & $X$ & Selectos & $X$ & Selectiva & $X$ & Orgánico & \\
\hline Metal & No Combust. & $X$ & Especiales & & Restos & & Inorgánico & $\mathrm{X}$ \\
\hline Metal no férreo & - & & - & & Restos & & - & \\
\hline Plásticos & Combustible & $X$ & Envases & $X$ & Envases & $X$ & Inorgánico & $X$ \\
\hline Materia Orgánica & Combustible & & Restos & & Restos & $X$ & Orgánico & $X$ \\
\hline Madera/celulosa & - & & - & & Restos & & - & \\
\hline Finos $-6 \mathrm{cms}$ & - & & Restos & & - & & Inorgánico & \\
\hline Textiles & - & & Restos & $X$ & Restos & $X$ & Inorgánico & \\
\hline Textil Sanitario & - & & Restos & & - & & Inorgánico & \\
\hline Otros & Indefinido & & Restos & & Restos & & Inorgánico & \\
\hline
\end{tabular}

X: A estos conceptos se les da prioridad de reciclaje. Fuente: Elaboración Propia. Múltiples fuentes.

por actores de la economía formal (empresas, organizaciones, sociedades y particulares) como informal (carretoneros, ropavejeros, pepenadores y tianguis). En Tokio la reutilización es también alta en el ámbito circunspecto, seguida de la de Madrid y París. Sin embargo, en el sector informal las figuras tienen una tendencia a la baja en relación al control más estricto de las políticas de recolección y a la misma autosuficiencia de los sectores involucrados. Lo mismo que ocurre con el manejo de los RI, específicamente los residuos de la construcción.

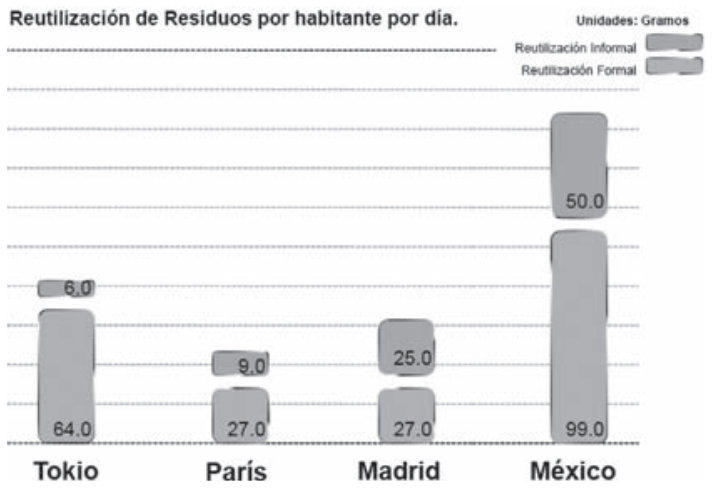

GRÁFICO 5. Fuente: Elaboración propia (datos: Tablas 1 y 2). 
El aprovechamiento de los residuos, resumido en este trabajo como transformación de la materia desechada, se puede separar en Compostaje y Reciclaje. Dividido a su vez en reciclaje directo (que se separa en origen y se lleva de forma directa a la planta de reciclaje) y reciclaje resultante de procesos de selección y tratamiento intermedio.

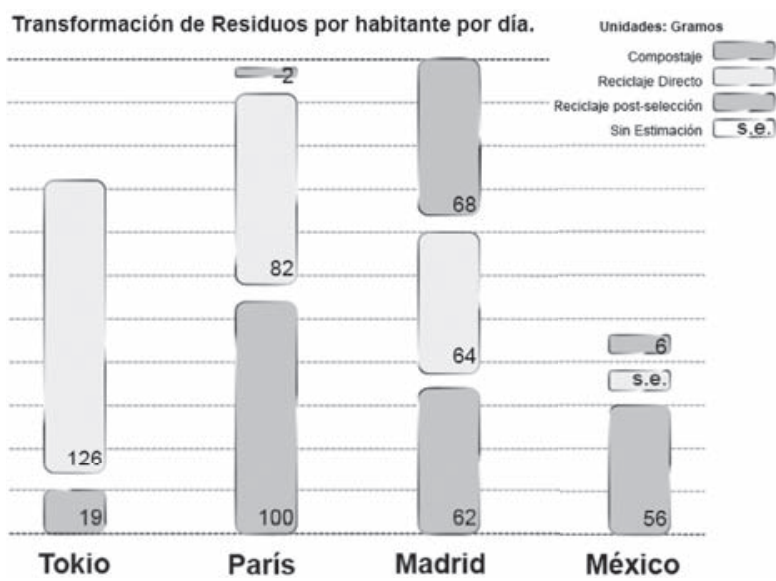

GRÁFICO 6. Fuente: Elaboración propia (Tablas 1 y 2).

La gráfica anterior refleja, a mayor detalle que en el Gráfico 3, las proporciones de materias transformadas o recuperadas del total de RD. Madrid con un mayor volumen de RD per cápita también es el que más residuos recupera, con un compostaje muy superior que el resto de las ciudades revisadas. En los residuos reciclados, sobresale Tokio con una mejor selección en fuente y París con la mayor eficacia en plantas de separación. La Ciudad de México es la menos eficiente, por debajo tanto en cantidad como en porcentaje de recuperación.

La recuperación de materia prima es muy distinta cuando revisamos el reciclaje de los RI. Madrid queda en último lugar, superada incluso en el concepto de "Compostaje" por los residuos recuperados de mercados, restaurantes y central de abastos en el DF. Tokio es la única ciudad cuyos resultados realmente destacan. Sometiendo a procesos de separación, trituración, gasificación, reducción, etc., el 98\% de sus RI, sin escatimar en gastos y proponiendo cada vez estándares más ambiciosos.

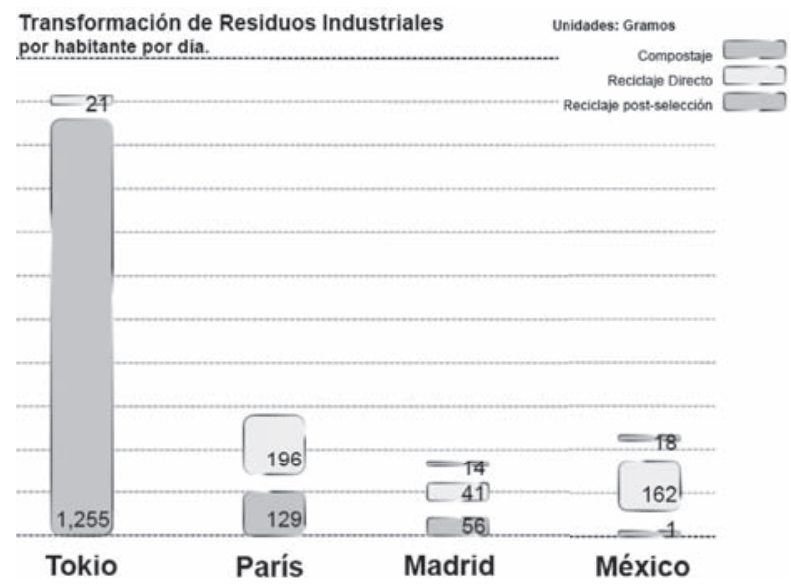

GRÁFICO 7. Fuente: Elaboración propia (datos: Tablas 1 y 2). 


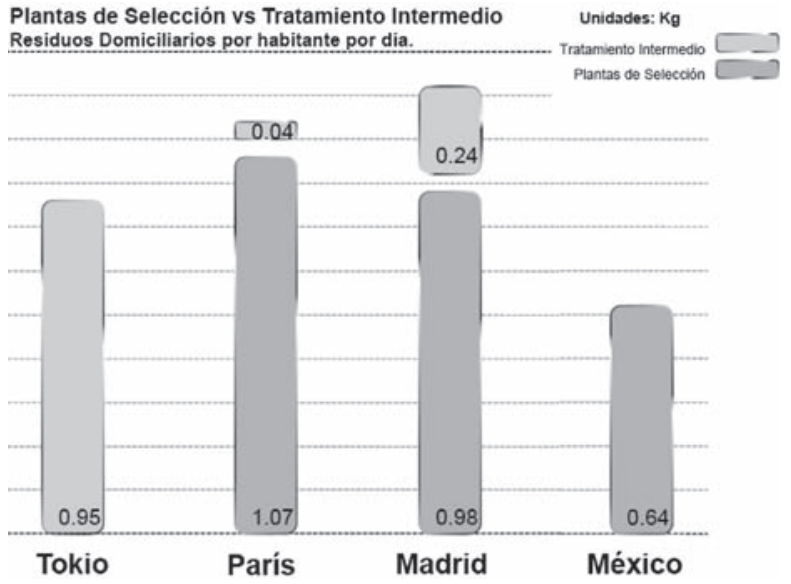

GRÁFICO 8. Fuente: Elaboración propia (datos: Tablas 1 y 2).

Los mismos resultados se repiten en las gráficas siguientes, mostrando la opción de tratamiento que escoge cada ciudad en función a sus posibilidades. Las transformaciones son un porcentaje que refleja la eficiencia práctica de los métodos de gestión seleccionados contra el volumen de residuos procesados.

Cuando se extrapolan los valores obtenidos en función a los porcentajes, las divergencias parecen atenuarse. No hay que olvidar que los porcentajes son sólo una herramienta que ayuda a complementar los elementos expuestos individualmente con anterioridad.

Esta gráfica destaca el orden ascendente de residuos domiciliarios que van a parar al vertedero,

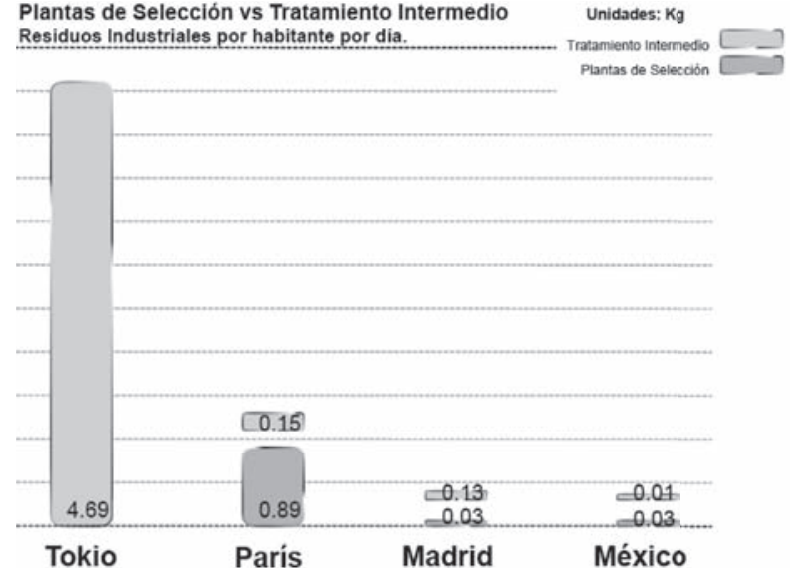

GRÁFICO 9. Fuente: Elaboración propia (datos: Tablas 1 y 2).

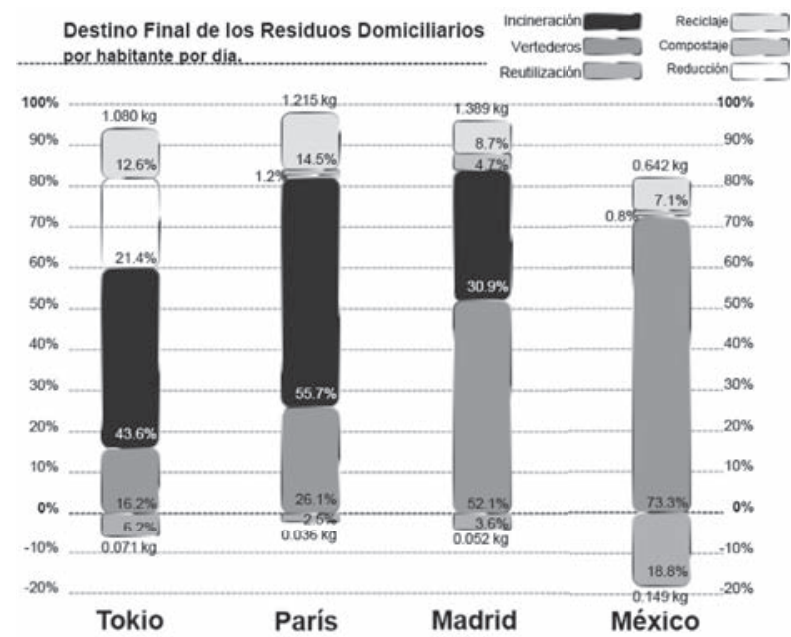

GRÁFICO 10. Fuente: Elaboración propia (datos: Figuras anteriores). 


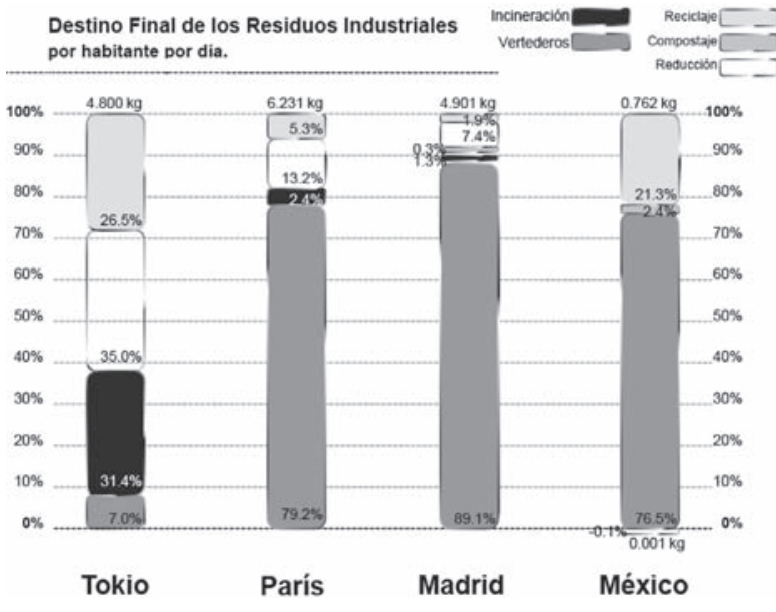

GRÁFICO 11. Fuente: Elaboración propia (datos: Tablas 1 y 2).

así como el orden descendente de residuos incinerados-reducidos. También la gran cantidad de residuos reutilizados del DF, con una proporción cercana a la quinta parte de la generación total.

En las tres primeras ciudades, tanto el incremento de residuos en vertedero como el decremento de incineración-reducción se mantienen. Inclusive el valor de reciclaje sigue el mismo patrón. Sin embargo, la misma figuración de porcentajes, atenúa en gran medida los datos de Destino Final de los RI. Lo que provoca que el DF, con datos contundentemente dispares, aparente una gran cantidad de residuos transformados y residuos en vertedero equiparables a los

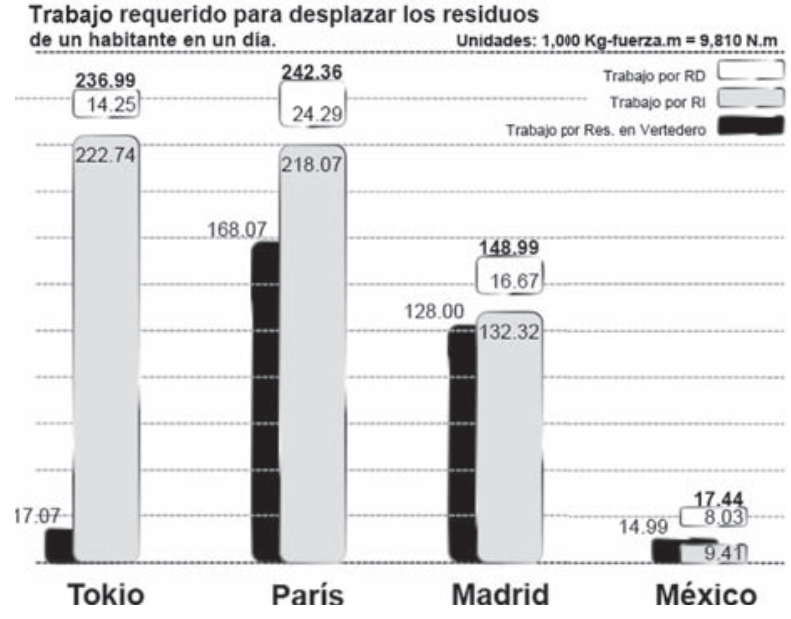

GRÁFICO 12. Fuente: Elaboración propia (datos: Tablas 1 y 2).

de París. Pero como se ha comentado en varias ocasiones, esta gráfica sólo reúne los datos anteriores.

Por último, hay que regresar a los datos cuantitativos puros para revisar el impacto territorial de los residuos. Las cantidades ya se han estudiado exhaustivamente en las gráficas anteriores, sin embargo, queda un dato que no se ha llevado a sus últimas circunstancias. La variable "desplazamiento" es uno de los datos más interesantes para el estudio del impacto de los residuos en un asentamiento humano.

Cada kilogramo de basura, dependiendo de donde se origine, su composición y su volumen, aunado a 
Tokio

\section{RESUMEN EN KG POR HABITANTE}

Reutilización $\mathrm{p} / \mathrm{h}$ ab/dia $\quad 0.06 \mathrm{~kg}$

Basura generada $\mathrm{p} / \mathrm{hab} / \mathrm{d}$

Basura Industria p/hab/dia

Desplazamiento promedio

Basura reciclada $p /$ hab/dia

Composta p/hab/dia (entrada)

Basura almacenada $p /$ hab/dia tendencia (5 años)

\section{París}

$1.08 \mathrm{~kg}$

$4.80 \mathrm{~kg}$

$30.51 \mathrm{~km}$

$\begin{array}{cc}1.42 & \mathrm{~kg} \\ - & \mathrm{kg} \\ 0.56 & \mathrm{~kg}\end{array}$

Madrid

$\begin{array}{rr}0.03 & \mathrm{~kg} \\ 1.39 & \mathrm{~kg} \\ 4.90 & \mathrm{~kg} \\ 24.82 & \mathrm{~km} \\ & \\ 0.22 & \mathrm{~kg} \\ 0.08 & \mathrm{~kg} \\ 5.16 & \mathrm{~kg} \\ \text { sube } & \end{array}$

México

$\begin{array}{rl}0.03 & \mathrm{~kg} \\ 1.21 & \mathrm{~kg} \\ 6.23 & \mathrm{~kg} \\ 28.53 & \mathrm{~km} \\ & \\ 0.51 & \mathrm{~kg} \\ 0.00 & \mathrm{~kg} \\ 5.31 & \mathrm{~kg} \\ \text { baja } & \end{array}$

$0.10 \mathrm{~kg}$

$0.64 \mathrm{~kg}$

$0.75 \mathrm{~kg}$

$12.50 \mathrm{~km}$

$0.22 \mathrm{~kg}$

$0.02 \mathrm{~kg}$

$1.20 \mathrm{~kg}$

constante $\leftrightarrow$

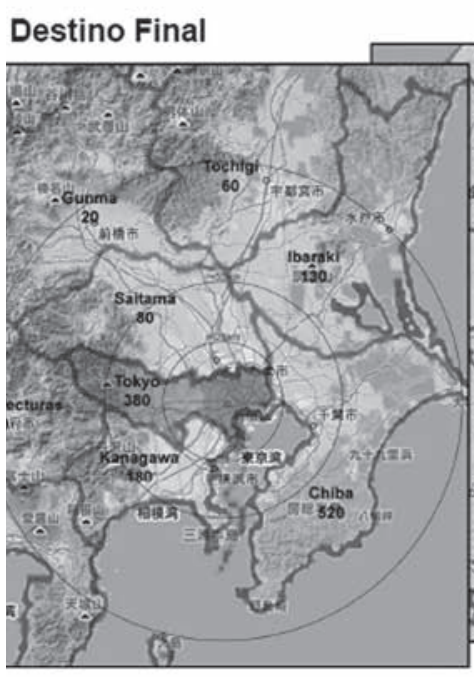

FUENTE: Tokyo Metropolitan Gobernment

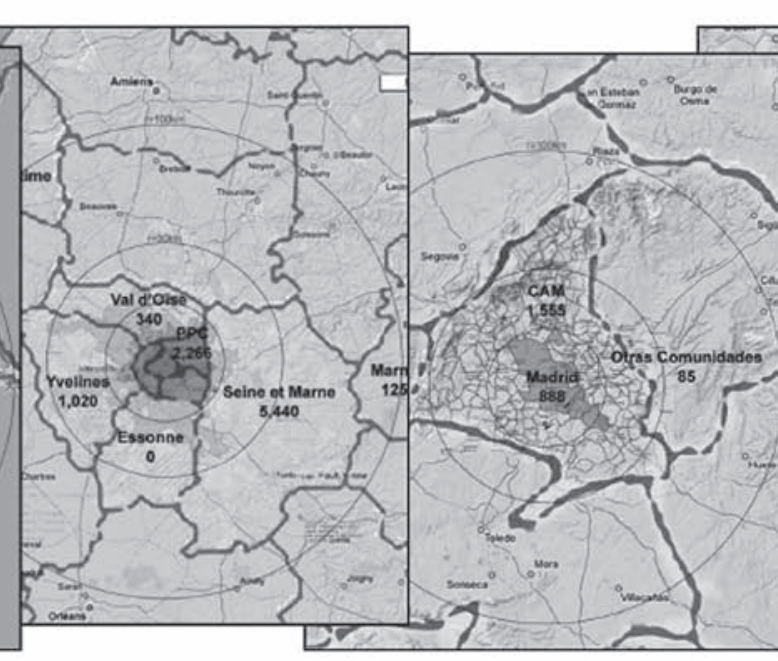

FUENTE: SYCTOM de Paris, Plan de Gestion pour Paris
FUENTE: Comunidad de Madrid

Unidades $=1,000$ toneladas
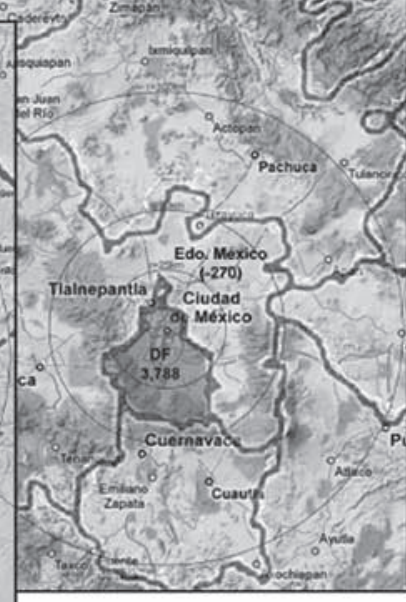

FUENTE: Instituto Nacional de Ecologis

FIGURA 5. Cuadro Resumen. Fuente: Elaboración propia, múltiples datos antes citados. 
los métodos de gestión llevados a la práctica, tiene un recorrido que requiere un esfuerzo específico. Es prácticamente imposible hacer un estudio riguroso con valores incuestionables, pero con los datos generales obtenidos y la disposición espacial de los principales vertederos, se puede llegar a un valor próximo a la realidad.

La relación de trabajo total es la simple multiplicación del peso de los residuos (en este caso en unidades de kilogramos fuerza) por la distancia que recorren para llegar a los lugares en donde se procesan o se dispone de ellos.

Con excepción de la ciudad de París, los vertederos que reciben los RD quedan dentro de las demarcaciones de cada área de estudio, a un promedio de 12 kilómetros del centro. Por otro lado, los residuos industriales tienen un destino final radicalmente distinto. Llegan a vertederos tan lejanos como a 150 km (en el caso de Japón) hasta vertederos tan próximos como los que reciben los RD.

En general, la distancia a la que se exportan los RI depende de la consolidación urbana, llevada a

210 revista invi № 70 / Noviembre 2010 / Volumen № 25: 181-222 la práctica como la extensión de la ciudad, fenómeno que es comúnmente explicado con el efecto NIMBY $^{29}$. La única excepción se da en la Ciudad de México, que a pesar de su rango cuenta con mucho menos RI, por lo que es capaz de recibirlos en el mismo vertedero de RD. La ciudad industrializada de mayor tamaño, en este caso Tokio, lleva los residuos a un promedio de $46.4 \mathrm{~km}$, mientras que París dispone de ellos a $35 \mathrm{~km}$ y Madrid a aproximadamente $27 \mathrm{~km}$ del centro de la ciudad.

\section{Conclusiones}

\section{NUESTRA REALIDAD A NIVEL CIUDAD}

Existe una disgregación morfológica de las grandes urbes que se ha potenciado a raíz de dos situaciones. Por un lado, la preocupación por la movilidad y los servicios, que se ha mantenido como una prioridad por más de 100 años y, por el otro, el metabolismo ${ }^{30}$ de la ciudad que presenta carencias al fungir como sistema abierto. Ambas situaciones empeoran cuando se promueve el paso de mercan-

29 NIMBY son las siglas de la frase "Not In My Back Yard", que representa la latente preocupación de la ciudadanía por colocar los servicios lo más lejos posible de su propiedad. Llevada a la práctica con gran parte de los equipamientos de recepción de residuos: incineradoras, plantas de tratamiento, reciclaje y, sobre todo, vertederos.

30 Analogía de los flujos económicos equiparable al proceso anabólico-catabólico de organismos biológicos, de los que se habló en el apartado anterior. 
cías que no atañen a la urbe. Dicho de otro modo, los inconvenientes de una ciudad crecen a medida que la información ${ }^{31}$ se acumula. La búsqueda de soluciones a dicho conflicto se dificulta, puesto que la situación puede observarse desde distintas perspectivas. Mientras que en el marco socioeconómico, el flujo de información es un concepto positivo (que presupone beneficios tangibles que radican en la vulnerabilidad de sus circunscritos), en el marco medioambiental representa un peligro.

Esta tesis se puede comprobar cuando se extrapolan los datos, de los residuos por ciudad, al contexto económico. En el sistema económico global, París es la Ciudad Global ${ }^{32}$ que ocupa un mayor rango (de las cuatro ciudades revisadas), Tokio le sigue de cerca, luego Madrid y al final México ${ }^{33}$. Los residuos siguen el mismo orden, pero en sentido inverso, en donde la ciudad menos desarrollada (en este caso, menos terciarizada) es la que requiere menos trabajo para disponer de sus residuos (Gráfico 12).

Siguiendo esta lógica, el tamaño de la ciudad y su población no son factores tan importantes como el flujo de productos y servicios derivados del con- sumo. Del mismo modo que el grado de bienestar puede corresponder con el PIB, el mismo bienestar con poca visión a futuro se puede traducir en desperdicios. El consumo excesivo se da cuando se descalifican las características de utilidad inherentes en objetos y son sustituidas por otras con un valor efímero basado en el símbolo que se les asigna. El valor efímero existe en el momento en que el costo ya no se deriva del esfuerzo de extracción o la utilidad del bien, sino parámetros ondulantes en donde desperdiciar una cosecha exitosa para que el precio por unidad incremente, se ha conseguido consolidar como un fenómeno aceptado e inclusive que parezca una "consecuencia lógica".

Los residuos gestionados, que se guían por la filosofía mercantilista, siguen siendo y continuarán surgiendo de la misma forma que siempre, pero en mayor cantidad y extendiendo los parámetros de lo que se percibe como un desperdicio "normal". En otras palabras, el consumismo aunado a la economía como instrumento que regula los recursos, conlleva a percibir algunos, que en otra época tenían una función, como inútiles. A pesar de que la generación de residuos aumenta como conse-

31 El centralismo de información que, basado en los flujos y el control, ha homogeneizado la transdisciplinariedad que caracteriza a las grandes urbes.

32 En su libro "Cities in Evolution", Patrick Geddes (1915) acuña el término World Cities para referirse a las ciudades que controlan una cantidad sumamente alta de negocios globales. GaWC, 2008. 
cuencia de dicho sistema económico, el desarrollo basado en el consumo puede seguir funcionando, siempre y cuando estructuremos y respetemos los límites dinámicos de crecimiento.

Los cambios físico-espaciales asociados al desarro$1 \mathrm{o}^{34}$ se presentan más rápido que la capacidad que ha tenido el ser humano de reaccionar ${ }^{35}$ a ellos, en donde las reservas que se han generado en el planeta a lo largo de eras geológicas solventan nuestra carencia en reflejos. La especie humana se adapta bien a los cambios y probablemente será capaz de hacer frente a la futura escasez de recursos no renovables, pero como aclara elocuentemente Girar$\operatorname{det}^{36}$, "la reacción retardada del ser humano no es algo inusitado sino una realidad recurrente".

\section{TEORÍA VS. PRÁCTICA}

Como se ha podido observar, las cuatro ciudades estudiadas son sumamente distintas y las diferencias subjetivamente revisadas podrían poner en duda las variables, por lo que hasta este momento he tratado de omitir cualquier juicio de valor que asignase alguna incertidumbre a los datos obtenidos. De esta forma espero que el lector fortalezca

34 Desarrollo en el sentido económico más puro (leer Naredo 1996).

35 En la segunda ley de la Termodinámica se estipula que a toda acción le corresponde una reacción de igual magnitud y en dirección contraria. En el caso del ser humano, la reacción ha sido ampliamente superada por la acción. Girardet, 1999. su propio punto de vista y mi opinión no lo eclipse, sino sea tomada como un mero complemento del mismo. Además que, persuadir a alguien que una ciudad es mejor o peor que otra, es una tarea prácticamente imposible.

Si cada persona es un mundo y la ciudad es un sistema complejo en donde habita un gran número de personas, entonces la metrópoli es un gran sistema en movimiento en donde chocan millones de mundos en todo momento. Las ciudades y, en especial las grandes ciudades, presentan múltiples realidades que van mutando y redefiniendo a sus habitantes a lo largo del tiempo. Cada una con ambientes tan diversos como las personas que alberga.

La teoría es un supuesto en el que se estima lo que va a suceder en un contexto en donde se controlan todas las variables. En la práctica, no todas las variables pueden controlarse, lo que provoca que la teoría no siempre se pueda llevar a cabo. Para este efecto, todos los planes e instrumentos que rigen u ordenan el comportamiento humano son teorías que buscan una oportunidad. Un ejemplo son las legislaciones que componen los sistemas jurídicos 
que, demostrando la cultura y las preocupaciones de una sociedad cambiante, deben ajustarse a las nuevas necesidades y actualizarse frecuentemente. Cuando la teoría no funciona es porque existen variables nuevas o no controladas que no se están tomando en cuenta. Se producen resultados inesperados que conllevan a revisar la hipótesis.

Los residuos en la teoría, son materiales abandonados que pueden causar efectos adversos en el entorno natural. Las soluciones que se han adoptado, se basan en criterios estudiados que han evolucionado en la historia de cada ciudad. Tokio ha tenido más tiempo conservando la misma iniciativa base, y ha conseguido avanzar en formar una estructura de servicios congruente con las posibilidades de su gente. París es la ciudad que tiene más ingresos y genera más desechos totales, además de invertir fuertemente en el desarrollo de tecnologías para perfeccionar el aprovechamiento energético. Madrid cuenta con infraestructuras que sobrepasan la necesidad real de vertido, sin embargo, también tiene deficiencias que se adjudican a la necesidad de adoptar iniciativas europeas que no toman en cuenta sus verdaderas necesidades. Por último, el DF es la ciudad con menos ingresos, menos inversiones en tecnología y mayor descontrol. Por lo mismo, bajo esta teoría, México debería ser la ciudad más sucia de todas.

En la práctica, la Ciudad de México sí es la que menos invierte en limpieza, la que menos control tiene, la que menos recicla, la que menos energía recupera, y probablemente la más caótica de todas. Pero por otro lado, es la que menos residuos genera, la que menos incinera, la que menos energía utiliza, la que menor costo implica, y no sólo eso, también es la que más residuos reutiliza. Debido al poco capital que se destina a los servicios, aunado a un sector informal que llena gran parte de los vacíos de los mismos, la Cd. de México es la que menos procesos de riesgo tiene (como incineraciones y tratamientos químicos). Incluso con la reciente aplicación de la nueva ley, en donde aún falta un largo recorrido para llevar la teoría de la composición de los residuos a una realidad, y la incapacidad para encontrar un nuevo sitio de vertido, en el DF aun se encuentran más ventajas que desventajas.

Los residuos, desde su manejo, recorridos y equipamientos especializados, tienen que ver con la ordenación del territorio, la movilidad y la sostenibilidad. Es un ámbito que depende de una exitosa actualización; manteniendo y, en muchos casos, desplazando sus infraestructuras, aunque sólo sea para adaptarse a los cambios demográficos y de sobreexplotación. Por otro lado, la basura es un sector impopular y muy pocos países cuentan con suficientes personas capacitadas para su gestión. En las palabras de Alfonso del Val, "Si en este momento nos dieran todo el dinero necesario para solucionar los problemas de residuos en España, no habría manera de llevarlo a cabo. En España no se 
cuenta con los especialistas suficientes ni siquiera para enseñar el tema a la generación siguiente".

Aunque el campo forme parte de los servicios básicos que tiene que contemplar cualquier ciudad desde su origen, los residuos son uno de los sectores más apartados del planeamiento y ordenación del territorio. Es verdad que son un problema que se ha sextuplicado en el tiempo de vida de una persona, y por su rápida propagación, son difíciles de comprender del todo, incluso para las ciudades que no llevan siglos de funcionamiento. Los servicios de recogida, con sus consecuentes ramificaciones, se han tenido que adaptar a la implementación de tecnologías e infraestructuras emergentes prioritarias, como fueron: autopistas, ensanches, plantas de energía, aeropuertos, infraestructuras militares, y algo más reciente, los electrodomésticos, centros logísticos, de distribución y otros. Tecnologías que cada vez son más efímeras y contienen más componentes en un mismo volumen de producto.

\section{DE LOS DOMÉSTICOS A LOS INDUSTRIALES}

En cierta forma los residuos nos traicionan; son culpables de exhibir nuestras intimidades al grado que, una bolsa de basura, puede revelar las características económicas, ecológicas y culturales de toda una población. Los residuos son un indica- dor que revela dramáticamente nuestro modo de $v i_{a}{ }^{37}$. Se asegura que la producción de desechos es inversamente proporcional al nivel de desarrollo de cada país. Después de analizar los datos de este trabajo, y de fuentes como la OECD y la ONU, podemos diferir con esta aseveración. Existen variables que nos impiden categorizar la producción de residuos sólidos sólo en base al desarrollo del país, el PIB o el ingreso per cápita.

Como si fuese un iceberg, sólo vemos una pequeña punta de la basura que generamos. Los ciudadanos tenemos hábitos que difieren unos de otros, pero todos cumplimos con rangos de generación que van de los 250 gramos por habitante al día, en algunas zonas de África, a 2,500 gramos, en algunos estados de EE.UU. El contraste es amplio, pero cuando revisamos el sector industrial cuyos procesos extractivos y productivos contribuyen, en forma de generación indirecta de los productos adquiridos, las diferencias se hacen exponenciales. En este sentido, la vulnerabilidad de una población es la que termina por traducirse en un mayor aprovechamiento de los recursos con los que cuenta.

Las fronteras no restringen la generación y, salvo el caso de los RD de Tokio, tampoco la disposición de los residuos. Las grandes cantidades de materia desechada se han convertido en una mercancía negativa; es decir, un producto que representa un cos-

37 Mallavan, 1986 
to alto para el productor. La gestión de los residuos se ha convertido en un problema generalizado que traspasa por mucho las fronteras que delimitan la ciudad. Este nuevo modelo de movilidad, obliga a las entidades a optar por soluciones generales que se puedan adoptar por varias naciones. Como fue el caso de Alemania, que tuvo que reducir sus exigencias para diversificar sus importaciones en la UE, o el caso de Japón en la APEC.

Aunque la movilidad no tiene sólo connotaciones negativas. La gran incidencia de RI provoca que se diversifiquen los mercados, donde las materias recolectadas se exportan al mejor postor; en el mejor de los casos, en su mismo continente. El único problema con los residuos industriales ocurre cuando el gasto energético, que implica el transporte, es mayor que el de extracción de los mismos. Fenómeno que ocurre más de la cuenta, debido al decremento de valor al que se someten las materias desechadas en muchos países.

Siguiendo con esta idea, los RD representan un problema medioambiental, por tratarse de una situación de carácter local. Por el contrario, los RI permean distintas capas del sistema, viajando de un lado a otro del planeta, por lo que personifican un problema de sostenibilidad. Lo que no quiere decir que los RI sean más graves que los domésticos, sólo que deben ser trabajados a escalas distintas.

Todo el mundo está de acuerdo en que debe existir un modelo que asegure los recursos. Sin embar- go, el modelo actual, basado en la negligencia, no es sostenible. Si no se quiere pasar de "una crisis global" a "la crisis del globo", se tiene que ajustar la postura que antepone el pseudo-bienestar económico al equilibrio eco-sistémico.

El sistema capitalista, basado en la valía y la plusvalía, establece una relación sostenida y creciente entre el hombre y los recursos. Pero tiene el grave problema que hay muchos agentes implicados con intereses creados que no quieren que la realidad económica se perciba en tiempo real. Es decir, las tendencias económicas tienen una cola, que no se termina hasta que a alguien le conviene que se termine. En esta etapa de la producción, en la que la escasez de materia prima, pura y superficial nos obliga a utilizar más energía para alcanzar los mínimos establecidos, el deterioro y la escasez de residuos llevan el mismo rumbo. Una tendencia que sólo podrá rebotar a manera de una serie de crisis intermitentes hasta que lleguemos al equilibrio, que de llegar muy tarde, será un equilibrio miserable para nuestra especie.

\section{LOS LÍMITES DE LOS SERVICIOS}

Hemos evaluado la situación actual de los residuos en donde existe una capacidad de carga planetaria que se está llevando al límite. Este límite tiene que ver con el consumo-desperdicio masivo y la incapacidad tecnológica de sustituir los ciclos naturales que procesan la materia. Lo que aún no se 
comenta es la otra variable que limita el sistema desde el principio: El propósito de los servicios.

Los servicios no son constructos tangibles que puedan sujetarse a fronteras físicas. Son actividades que pretenden cumplir con expectativas de los servidos y por lo tanto ilimitables. Sin embargo, una barrera no es necesariamente física, puede ser una idea llevada a la práctica. En el caso de los servicios de recogida, el límite tiene que ver más con la arbitrariedad de la frontera en sí misma. Es decir, con la noción de cuál es el máximo aprovechable de la cantidad generada y discutir la manera de llegar al tope. La eficiencia máxima, es cuando se consigue el 100\% de lo reciclable y en donde todos los equipamientos funcionan con los volúmenes para los que fueron diseñados.

Tal vez se consiga explicar por qué la ciudad es la figura de crecimiento demográfico menos insostenible encontrada por el ser humano. También se puede justificar la generación de residuos sólidos como una necesidad de subsistencia y una forma natural de transformar la materia prima. Incluso podemos llegar a decir que, para generar energía de biomasa, tenemos un recurso sostenible a proyecciones de mediano plazo. Sin embargo, en el marco en donde los servicios se destinan a librar a la población de su desperdicio, la reutilización, la transformación y la disposición final de la materia es el último indicador que nos puede llevar a justificar la sostenibilidad de la urbe.
Es bastante difícil obtener datos que no procedan de percepciones injustificadas cuando la basura sigue siendo un servicio subordinado a valoraciones subjetivas en un ámbito restrictivo. Por ejemplo con el caso del CO2: Es un recurso que cuando se encuentra en exceso en la atmósfera se convierte en un residuo y que mal manejado se percibe como un agente contaminante; cuando lo único que siempre ha sido, es un compuesto residual que tenemos que aprender a controlar.

Todas las ciudades se pueden visualizar como sistemas dinámicos o sistemas complejos que cambian a través del tiempo, esto provoca que sea imposible abarcarlos utilizando meros indicadores de sostenibilidad. Para lograr seccionar el estado actual de los residuos, en un marco temporal determinado, nuestra mejor opción es ligarlos a las entidades inmóviles menos perecederas: Los vertederos.

\section{VERTEDEROS, PREVISIÓN Y LEJANÍA}

Los sistemas de tratamiento (reciclaje y compostaje), tratamiento intermedio e incineración (con o sin recuperación de energía), han provocado que el porcentaje relativo de desperdicios vaya decreciendo, sin embargo, las tendencias de consumo y el crecimiento demográfico hacen que el volumen de los residuos siga en aumento.

El vertedero aún es la mejor solución a la que ha llegado el hombre para minimizar las consecuen- 
cias negativas de sus residuos. En México se conoce como Relleno Sanitario, en Madrid: Vertedero Controlado, en París: Centro de Enterramiento Técnico (Centre d'Enfouissement Technique) y en Tokio: Lugar de Disposición Final (最終処分場) ${ }^{38}$. Cada uno de éstos se selecciona tomando en cuenta la accesibilidad, la capacidad de carga y, tanto en París como en Madrid y en México, tiene que ser aprobado por un estudio Medioambiental desarrollado por el Ministerio de Ecología o equivalente. París legisla el área de la que se puede disponer cada año, ajustando los nuevos reglamentos, abriendo nuevos espacios de vertido equivalentes a los que se clausuran. Las demás ciudades simplifican con un solo gran equipamiento. Tokio prevé una capacidad suficiente para incorporar los RD de los próximos 50 años, Madrid tiene contemplado utilizar su Vertedero de 8 a 15 años más, mientras México está clausurando su único Relleno Sanitario en estos momentos, sin previsión alguna para la nueva instalación ${ }^{39}$.

La distancia a los Vertederos de RD varía poco en las 4 ciudades. París es la que tiene un promedio más lejano a $20 \mathrm{~km}$, Tokio a $13 \mathrm{~km}$, México a $12.5 \mathrm{~km}$, y Madrid a $12 \mathrm{~km}$ de distancia. Los gran-

38 En Tokio también se le conoce como “Terreno Relleno" (埋立地) por tratarse de tierras ganadas a la Bahía.

39 En estos momentos está en construcción otro tipo de Relleno Sanitario que incluirá incineración, composta y otros procesos de sellado a varios kilómetros de distancia del Vertedero saturado actual. des vertederos tienen problemas por el simple motivo de concentrar una gran cantidad de residuos generados por una población en diminutas unidades de tierra. Desechos que producen lixiviados capaces de contaminar las capas freáticas, de emitir gases peligrosos así como de efecto invernadero, y malos olores.

La saturación de los sistemas locales, como sucede en los vertederos, es conocida como proceso de eutrofización. "Un río, un lago o un embalse sufren eutrofización cuando sus aguas se enriquecen en nutrientes. Podría parecer a primera vista que es bueno que las aguas estén bien repletas de nutrientes, porque así podrían vivir más fácilmente los seres vivos. Pero la situación no es tan sencilla. El problema está en que si hay exceso de nutrientes, crecen en abundancia las plantas y otros organismos. Más tarde, cuando mueren, se pudren y llenan el agua de malos olores y le dan un aspecto nauseabundo, disminuyendo drásticamente su calidad. El proceso de putrefacción consume una gran cantidad del oxígeno disuelto y las aguas dejan de ser aptas para la mayor parte de los seres vivos. El resultado final es un ecosistema casi destruido" ${ }^{40}$.

\section{Echarri, 1998.}


Por esta razón, la reducción de los sitios de vertido en función al compostaje y reciclaje es muy importante. Cuando no se toman en cuenta los residuos rescatables, y nos limitamos a producir sólo con materias primas recién procesadas, no sólo la explotación y la entropía aumentan, también el riesgo de eutrofización.

\section{EL POTENCIAL DEL RECICLAJE}

El porcentaje de masa que se recicla en las ciudades, al día de hoy, está muy por debajo de sus posibilidades. Las principales razones son la contaminación de los materiales al entrar en contacto unos con otros y el costo de separación elevado cuando se compara con el de extracción de materia prima de la naturaleza.

Si habláramos de la ciudad ideal, que flota en un mar de materias primas superficiales, se alimenta de fuentes de energía cercanas y alberga a una población consciente de su impacto en el contexto; entonces se puede hablar de una solución utópica para el caso de los residuos. Mientras tanto, la mejor forma en que una ciudad puede disponer de sus desechos es a la manera de un sistema complejo en el que las actividades se complementan. Al igual que en el ámbito productivo que lo precede, la ciudad debe ser capaz de generar múltiples or-

218 revista invi № 70 / Noviembre 2010 / Volumen № 25: 181-222 ganismos cuya función sea catabolizar las materias desperdiciadas para extraer todo lo útil. La competencia es la única forma de conseguir una industria transformadora eficiente. Vista mucho más allá de la privatización en un ámbito en el que el precio de la materia desechada permita que surjan servicios medianos y pequeños que complementen a las grandes industrias y antepongan la eficiencia energética a la utilidad bruta. Una facilidad que sólo la cercanía y la variedad de disposición son capaces de ofrecer, y que comprendido por las iniciativas adecuadas, evitaría que fuese abordado sólo por los sectores sociales más vulnerables de cada país.

Para llegar a un cambio tan radical, primero tendrán que existir ajustes en la percepción y sobre todo en el valor real del recurso natural. Sólo entonces, el comportamiento de los agentes económicos permitirá revalorizar lo que hoy en día se da por un hecho. Cuando materiales como el petróleo y el carbón lleguen a un costo estratosférico que redimirá el espectro de los materiales sub-valuados.

Todavía en esta primera década del siglo XXI, el tema de los residuos sólidos atañe a todos los asentamientos humanos y se proyecta como uno de los principales problemas ${ }^{41}$ a corto, mediano y largo plazo.

41 Siendo el otro gran problema, la extracción de recursos no renovables. Ambos actores principales en la alteración de ecosistemas y ciclos bio-geoquímicos que, por la sobrexplotación y exceso de generación de residuos, son los responsables de todos los procesos humanos irreversibles de gran escala alrededor del globo. Contribuyendo incluso en algunos fenómenos meteorológicos. 
Al tomar cada ciudad y contrastar su desempeño, se llegó a resultados sencillos y lógicos de los sistemas empleados así como su impacto ecológico en la realidad de cada ciudad. Viendo en los distintos casos cuáles son los aspectos débiles en la gestión de residuos sólidos, enfocado más a la práctica que a la teoría. La basura siempre ha sido un sector oculto que difícilmente se puede percibir en toda su extensión. Este carácter secretivo llega al extremo en que los gobiernos obvian variables que desvirtúan la información resultando en datos cuestionables. A comparación de otras áreas de la ciudad, el manejo de los residuos es un programa poco desarrollado. Lleno de vacíos en su sistema organizativo. Es interesante y conviene saber cómo y por qué somos ineficientes en unas áreas y eficientes en otras. Mientras distintas situaciones conviven en el planeta con procesos autosuficientes, los residuos suelen ser servicios sobreprotegidos, con poco involucramiento por parte de los consumidores y los mismos dueños de la industria de la región. En otras palabras, podemos asegurar que el futuro de la ciudad continuará dependiendo de nuestra forma de percibir y administrar el entorno. Por lo que no queda otra alternativa que cumplir con la ardua tarea de ordenar para reducir procesos, incrementar aportaciones energéticas al medio y perdurar todo el tiempo que el planeta nos lo permita.

\section{ACRÓNIMOS}

\begin{tabular}{|c|c|}
\hline APEC & Asia Pacific Economic Council \\
\hline ASEAN & $\begin{array}{l}\text { Association of South-East Asian Na- } \\
\text { tions }\end{array}$ \\
\hline CAM & Comunidad Autónoma de Madrid \\
\hline DF & Distrito Federal (México) \\
\hline EE.UU. & Estados Unidos \\
\hline IUCN & Word Conservation Council \\
\hline OECD & $\begin{array}{l}\text { Organization for Economic Co-opera- } \\
\text { tion and Development }\end{array}$ \\
\hline RSU & Residuos Sólidos Urbanos \\
\hline RD & Residuos Domiciliarios \\
\hline RI & Residuos Industriales \\
\hline SIG & Sistemas Integrados de Gestión \\
\hline SCP & $\begin{array}{l}\text { Sustainable Cities Program of UN- } \\
\text { CHS }\end{array}$ \\
\hline TMG & Tokyo Metropolitan Government \\
\hline $\mathrm{UE}$ & Unión Europea \\
\hline UN / ONU & $\begin{array}{l}\text { United Nations / Organización de las } \\
\text { Naciones Unidas }\end{array}$ \\
\hline UNEP & United Nations Environment Program \\
\hline UNCHS & $\begin{array}{l}\text { United Nations Centre for Human } \\
\text { Settlements }\end{array}$ \\
\hline ZMVM & $\begin{array}{l}\text { Zona Metropolitana del Valle de Mé- } \\
\text { xico }\end{array}$ \\
\hline
\end{tabular}




\section{Bibliografía y Referencias}

BAUDRILLARD, JEAN. Réquiem por los media En Crítica de la Economía Política del Signo. 6a ed. México D.F. Siglo XXI. 1991. 249 pp.

BOE, Boletín Oficial del Estado. Plan Nacional Integrado de Residuos para el período 2008-2015. BOE, Número 49. cve: BOE-A-2009-3243. España. 2009. (Jueves 26 de febrero de 2009).

CASTELLS, XAVIER ELIAS. Reciclaje de Residuos Industriales. Madrid, Diaz de Santos. 2000. 624 pp.

CET, centre déenfouissement technique. Guide méthodologique pour l'Evaluation des Incidences sur l’Environnement. Région Wallonne. 2007. p. 7-10.

CM. Comunidad de Madrid [En línea]. [Fecha de consulta: marzo de 2009]. Disponible en: http:// www.madrid.org/cs/Satellite?pagename=Comuni dadMadrid/Home

CORTINAS DE NAVA, CRISTINA. MANUAL 3. Valorización de residuos, participación social e innovación en su gestión. Manuales para regular los residuos con sentido común. México, 2003.Grupo Parlamentario del PVEM.

CRAN, Centro de Recursos Ambientales de Navarra Materiales educativos sobre residuos sólidos urbanos. Gobierno de Navarra. Fundación Centro de Recursos Ambientales de Navarra. Pamplona, España, ECOEMBES. 2006.

DEL VAL, ALFONSO. Del Consumo al Consumismo. [En línea]. ConsumeHastaMorir. Mayo 2004.
Disponible en: http://www.letra.org/spip/article. php?id_article $=2773$

DEL VAL, ALFONSO. El Libro del Reciclaje. Manual para la recuperación y aprovechamiento de las basuras. 3a Edición. Barcelona, Integral. 1997. Monográfico No. 25

ECHARRI, LUIS. Ecosistemas. Ciclos de los elementos. [En línea]. Ciencias de la tierra y el medio ambiente. 1998. Disponible en: http://www.tecnun.es/asignaturas/Ecologia/ Hipertexto/04Ecosis/130Ciclos.htm

FARIÑA TOJO, JOSÉ Y RUIZ SÁNCHEZ, JAVIER. Orden, desorden y entropía en la construcción de la ciudad. Urban (7): 8-15, 2002.

FISCHER-KOWALSKI, M., HABERL, H. Tons, Joules and Money. Modes of Production and their Sustainability Problems. Society and Natural Resources, 10(2): 61-85. 1997

GARDNER, GARY Y SAMPAT, PAYAL. Hacia una economía de materiales sostenible. La Situación del Mundo. En: Informe de Worldwatch Institute sobre Medio Ambiente y Desarrollo, Madrid: FUHEM, 1999. p. 91-123.

GAWC, Globalization and World Cities. The World According to GaWC 2008. [En línea]. Globalization and World Cities Study Group and Network (GaWC). Loughborough University. [Fecha de consulta: 07 mayo de 2008]. Disponible en: http://www.lboro.ac.uk/gawc/world2008t.html 
GDF, Gobierno del Distrito Federal. Manejo de los residuos sólidos [En línea]. [Fecha de consulta: diciembre de 2009]. Disponible en: http://www. obras.df.gob.mx/servicios_urbanos/residuos_solidos.html

GEDDES, PATRICK. Cities in Evolution. An Introduction to the Town Planning Movement and to the Study of Civics. London, Williams \& Norgate. 1915. $409 \mathrm{p}$

GIRARDET, HERBERT. Cities, People, Planet, Liveable cities for a sustainable world. Chichester, Wiley Academic. 2004. 304 p.

GIRARDET, HERBERT. Creating Sustainable Cities. Dartington, Green Books. 1999. 77 p.

GIRARDET, HERBERT. Rethinking Cities [En línea]. Big Picture TV. 2006 Disponible en: http://www. bigpicture.tv/speakers/herbert_girardet

GIRARDET, HERBERT. Urban Sustainability [En línea]. Big Picture TV. 2006 Disponible en: http://www. bigpicture.tv/speakers/herbert_girardet

GODF. Gaceta Oficial del Distrito Federal. Gaceta Oficial del Distrito Federal. No. 436, 7 de octubre de 2008. [En línea]. México D.F. Disponible en: http://www.consejeria.df.gob.mx/gacetas.php

HERNÁNDEZ AJA, AGUSTíN. Calidad de vida y medio ambiente urbano. Indicadores locales de sostenibilidad y calidad de vida urbana. [En línea]. Revista INVI, 24(65): 79-111. Mayo 2009. Universidad de Chile. Disponible en: http://www.scielo. cl/scielo.php?script=sci_arttext $\&$ pid $=$ S0718 $83582010000100005 \& \operatorname{lng}=$ es $\&$ nrm=iso\&tlng=es
IBÁÑEZ, JESÚS. Los futuros de la ciudad. Alfoz (57): 55-66. 1988.

INSEE. Institut national de la statistique et des études économiques: Accueil [En línea]. [Fecha de consulta: Octubre 2009]. Disponible en: http://www. insee.fr/

JICA, Japan's International Cooperation Agency. Estudio sobre el manejo de los residuos sólidos para la Ciudad de México de los Estados Unidos Mexicanos. Informe Final Vol. 1. GDF. Japón, JICAKokusai Kogyo CO. 1999.

MALLAVAN, ANNE-MARIE, MIMOUN, NORBERT Y ROTMAN, GILLES. La croissance des déchets ménagers. Economie et statistique. 185(1): 57-64. 1986.

MATSUTO, TOSHIHIKO. Residential solid waste generation and recycling. En: Proceedings of International Symposium and Workshop on Environmental Pollution Control and Waste Management. 7-10 January 2002, Tunis (EPCOWM'2002), p.187-192.

NARED0, JOSÉ MANUEL. Sobre el origen, el uso y el significado del término sostenible.[En línea] Documentación social, (102). 1996. Disponible en: http://habitat.aq.upm.es/cs/p2/a004.html

OECD, Organization for Economic Co-operation and Development. Gross domestic product (expenditure approach). Annual HVPVOB: Per head, US \$, constant prices, constant PPPs, OECD base year. 2009. [En línea] [Fecha de consulta: 30 de Marzo 2009]. Disponible en: http://webnet.oecd.org/wbos/index.aspx 
ORDIF. Observatoire régional des déchets d'Tle-deFrance. [En línea]. [Fecha de consulta: Octubre 2009]. Disponible en: http://www.ordif.com/public/

PGP, Plan de Gestion pour Paris. Déchets du BTP (Bâtiment et des Travaux Publics) - Plan de Gestion pour Paris et la Petite couronne. Direction régionale de l'Équipement d'île-de-France. Division nuisances ressources sécurité. 2006 (Data, Juillet 2004)

REES, WILLIAM E. Ecological Footprint Analysis: A Tool for Regional Sustainability. A Presentation to: The International Sustainability Conference, Fremantle, Western Australia. 2003. (presentada el 19 Sept, 2003).

SMN, Servicio Meteorológico Nacional. Informe Climatológico Ambiental del Valle de México 2005. [En línea]. Secretaría del Medio Ambiente. Gobierno del Distrito Federal. 2008. Disponible en: http://www.sma.df.gob.mx/sma/index. php?opcion $=26 \&$ id $=378$

SYCTOM, syndicat intercommunal de traitement des ordures ménagères. Le SYCTOM de l'Agglomération parisienne. Un syndicat au service des communes pour recycler et valoriser les déchets ménagers. 2006. (Septembre 2006).

TANAKA, MASARU. Symposium on the Challenge of Asian Region Toward 3Rs [en linea]. EN: Asia 3R Conference (2006, Tokyo, Japan). Okayama University. 2006. Disponible en: http://www.env. go.jp/recycle/3r/en/asia/02_05/01.pdf
TMG, Tokyo Metropolitan Government. Recursos de Internet. En línea. 2009. [fecha de consulta: abril del 2009]. Disponible en: http://www.metro.tokyo.jp/ENGLISH/index.htm

UKEO, United Kingdom Economic Outlook.UK Economic Outlook, March 2007. PricewaterhouseCoopers. March 2007, Pp. 3-8

UN, United Nations. Indicators of Sustainable Development: Guidelines and Methodologies. [en linea] 2001. Disponible en: http://www.un.org/ esa/sustdev/natlinfo/indicators/isdms2001/isdms200lisd.htm

UN, United Nations. [Recursos de Internet]. [En línea]. 2009. [fecha de consulta: mayo del 2009]. Disponible en: http://www.un.org/en/index.shtml

UN, United Nations. World Urbanization Prospects: The 2005 Revision. United Nations, Department of Economic and Social Affairs, Population Division. 2006. Working Paper No. ESA/P/WP/200.

UNEP, United Nations Environment Programme.Total waste generation in 2001, selected countries, UNEP/GRID-Arendal Maps and Graphics Library. [En línea]. 2004. [fecha de consulta: abril del 2009] Disponible en: http://maps.grida.no/go/ graphic/total-waste-generation-in-2001-selectedcountries

WCED. Report of the World Commission on Environment and Development: Our Common Future. [En línea]. Disponible en: http://www.un-documents.net/wced-ocf.htm 